OSNEY MONTEIRO CARVALHO

\title{
ESTRATÉGIAS PARA OCUPAÇÃO DA REDE HOTELEIRA DE BRASÍLIA NOS FINAIS DE SEMANA
}

Universidade de Brasília - UnB

Brasília - DF

2004 
UNIVERSIDADE DE BRASÍLIA

CENTRO DE EXCELÊNCIA EM TURISMO

Especialização para Docentes em Turismo e Hospitalidade

\section{ESTRATÉGIAS PARA OCUPAÇÃO \\ DA REDE HOTELEIRA DE BRASÍLIA \\ NOS FINAIS DE SEMANA}

Monografia apresentada ao Centro de Excelência em Turismo, da Universidade de Brasília, para a obtenção do título de Especialização para Professores e Pesquisadores em Turismo e Hospitalidade.

Orientador: Prof. Dr ${ }^{\mathrm{a}}$ Tereza Negrão

Osney Monteiro Carvalho

Brasília

2004 
Carvalho, Osney Monteiro

Estratégias para ocupação da rede Hoteleira de Brasília nos finais de semana/ Osney Monteiro Carvalho.

$50 \mathrm{f}$ :

Monografia (especialização). Universidade de Brasília. Centro de Excelência e Turismo. Brasília, 2003.

Área de concentração: 1. Hotelaria 2. Turismo 3. Planejamento Estratégico

4. Monografia 


\section{AGRADECIMENTOS}

A Deus.

Meus sinceros agradecimentos aos meus pais, pelo incentivo, dedicação e carinho. Também a minha irmã, que me deu muito apoio.

Imenso agradecimento a minha orientadora, Professora Tereza Negrão e a minha coordenadora Tânia Montoro, sem elas não teria conseguido. 


\section{RESUMO}

A pesquisa tem como Plano de Observação a cidade de Brasília e, com objeto de estudo, a rede hoteleira, na recorte dos Hotéis “4 estrelas”.

Objetivou-se levantar a taxa de ocupação aos finais de semana, tendo como hipótese a baixa performance do setor, devida à falta de divulgação e estratégias adequadas.

O suporte empírico da pesquisa inclui documentos da ABIH Associação Brasileira da Indústria de Hotéis e do C\&B Convention \&Visitors Bureau, aplicação de questionários e material iconográfico.

O estudo conclui apresentando possibilidades, para dinamização do setor caso estratégias sejam adotadas.

PALAVRAS-CHAVE: Hotelaria, viagens de negócios e turismo, promoções, planos de estratégias, divulgação, sazonalidade, feiras comerciais e Brasília. 


\begin{abstract}
The following research central bedding the systematic obervation of the occupetion of the hotel sector in its four star hotel category.

Its main to gather information about the occupation rate on the weekends taking into consideration that the low performance of the sectors is due to the lack of proper promotional activity and strategies.

The empirical support of the research includes, besides data from ABIH- Brazilian Association of the Hotel Industry and from C\&VB Convention \& Visitors Bureau, the use of questionnaires and iconographic material.
\end{abstract}

The study is concluded by presenting possibilities for more dynamic actions for the hotel sector in case the strategies suggested are adopted.

KEYWORDS: Hospitality, business and holiday trips, discounts, strategic plans, promotional activity, seasonal occupation. 


\section{SUMÁRIO}

LISTA DE TABELAS …............................................................................ VI

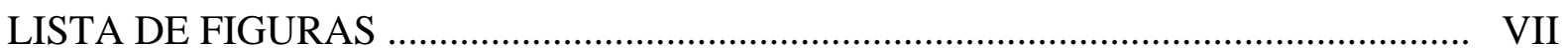

LISTA DE GRÁFICOS …............................................................................. VII

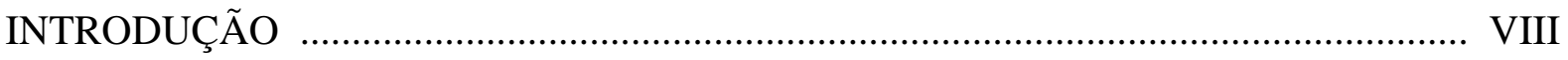

CAPÍTULO 1 - MERCADO DO TURISMO …....................................................... 1

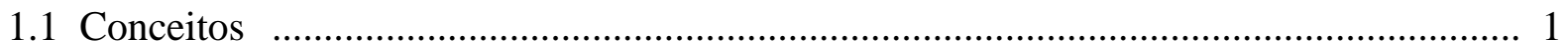

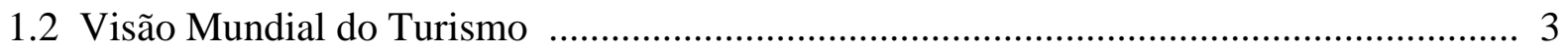

1.3 Análise do Turismo no Brasil ........................................................................................ 5

CAPÍTULO 2 - PLANEJAMENTO ESTRATÉGICO ..................................................... 10

2.1 Considerações Sobre Meios de Hospedagem e Empresa Hoteleira ............................... 10

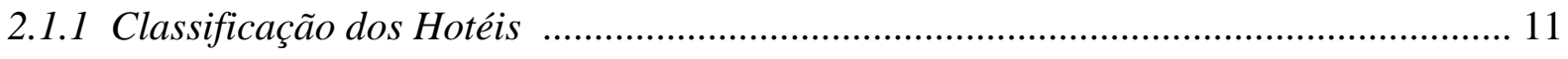

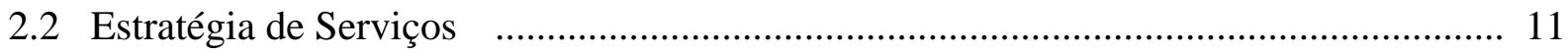

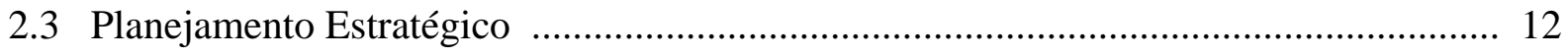

2.3.1 O processo de Planejamento .............................................................................. 13

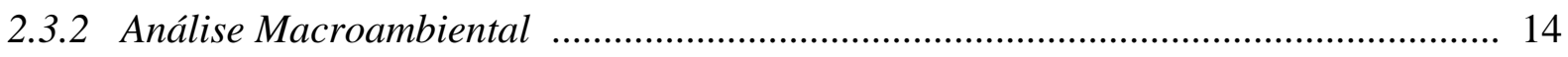

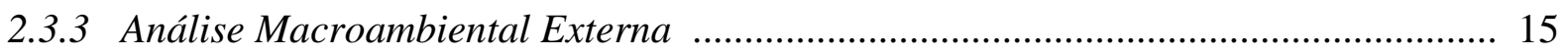

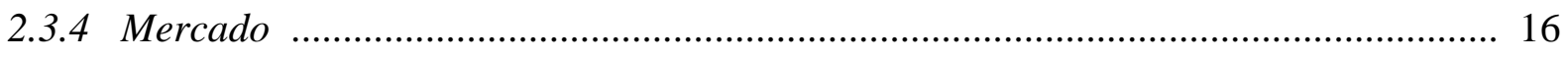

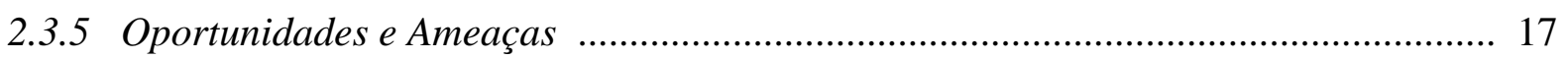

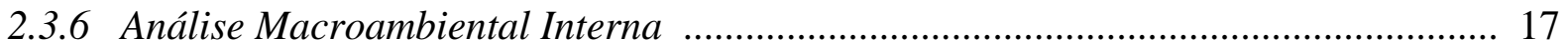

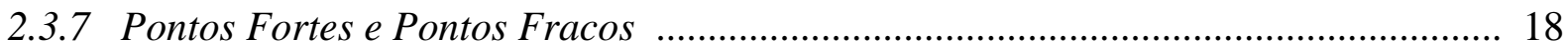

2.3.8 Objetivos do Planejamento Estratégico ................................................................ 19 
CAPÍTULO 3 - PONTENCIALIDADE DE BRASÍLIA PARA O TURISMO 22

3.1 História de Brasília 22

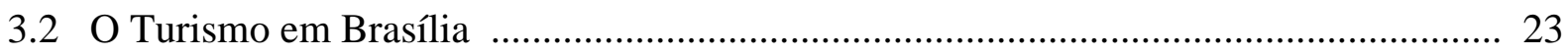

3.3 Parque Hoteleiro de Brasília ................................................................................. 28

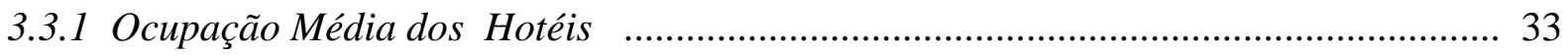

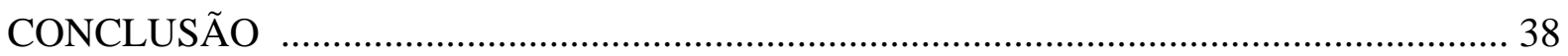

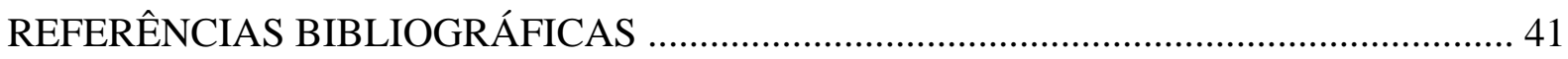

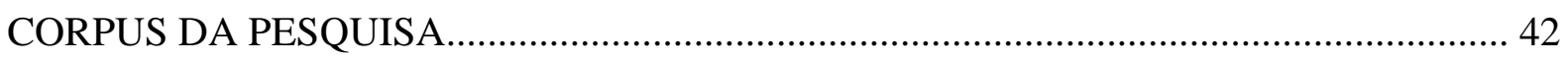

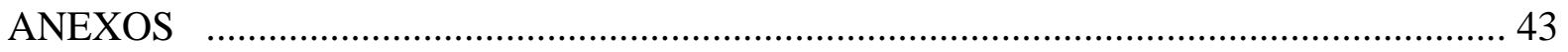

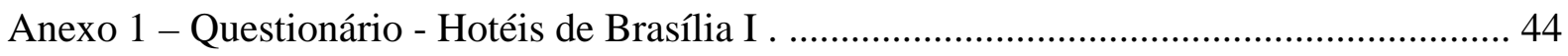

Anexo 2 - Questionário - Hotéis de Brasília II.................................................................. 45

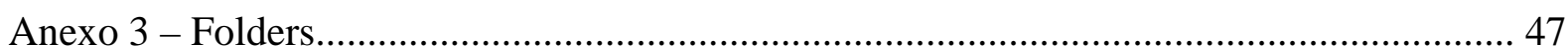




\section{LISTA DE TABELAS}

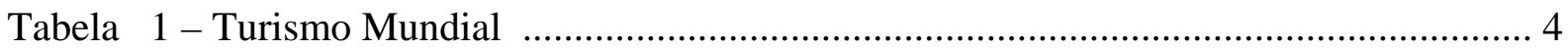

Tabela 2 - Turismo Evolução do Turismo no Brasil .............................................................. 6

Tabela 3 - Evolução dos Recursos Para Marketing e Propaganda no Orçamento da EMBRATUR, do período de 1995 a 2000 (em R\$) …...................................... 7

Tabela 4 - Motivo das Viagens de Estrangeiros Para o Brasil (em \%) ............................... 8

Tabela 5 - Insatisfação dos Turistas Estrangeiros (em \%) ............................................... 9

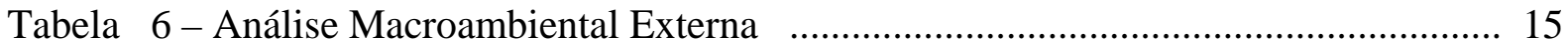

Tabela 7 - Análise Macroambiental Externa Oportunidades e Ameaças ........................... 17

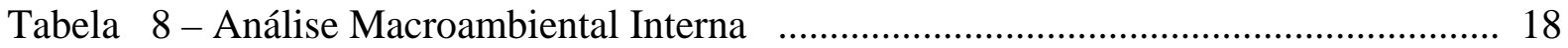

Tabela 9 - Exemplo de Análise Macroambiental Interna ................................................ 19

Tabela 10 - Perfil Anual do Turista Brasileiro nos Hotéis de Brasília .............................. 24

Tabela 11 - Perfil Anual do Turista Estrangeiro nos Hotéis de Brasília ............................. 25

Tabela 12 - Evolução do Parque Hoteleiro de Brasília …................................................. 30

Tabela 13 - Ocupação Semanal na Alta Temporada ............................................................ 33

Tabela 14 - Ocupação Semanal na baixa Temporada ....................................................... 24

Tabela 15 - Ocupação Média Mensal .................................................................................. 34 


\section{LISTA DE FIGURAS}

Figura 01 - Processo de Planejamento - Esquema Básico ................................................... 14

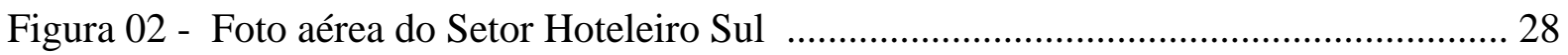

Figura 03 - Foto aérea do Setor Hoteleiro Norte ................................................................... 29

\section{LISTA DE GRÁFICOS}

Gráfico 01 - Local de Hospedagem dos Turista de Brasília ................................................ 23

Gráfico 02 - Evolução do Parque Hoteleiro de Brasília.......................................................... 27

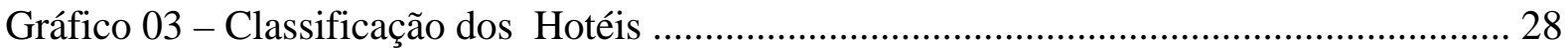

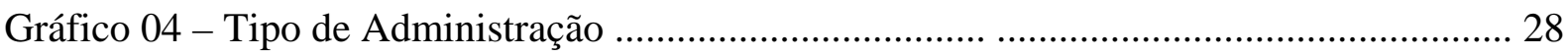

Gráfico 05 - Ocupação Média da alta e baixa temporada................................................. 29

Gráfico 06 - Se o Hotel tem promoções nos finais de semana............................................. 30

Gráfico 07 - Se o Hotel tem descontos nos finais de semana............................................... 31

Gráfico 08 - Se tem divulgação dessas promoções ..................................................................31 


\section{INTRODUÇÃO}

A competitividade e a constante evolução na hotelaria ressaltam, dentre outras, a importância de se analisar o seu aspecto econômico de forma segmentada. Nesse sentido, a hotelaria destaca-se como um setor eminentemente atrativo para a geração de negócios, proporcionando transformações significativas ao desenvolvimento socioeconômico regional.

No Capitulo I, analisou-se o panorama brasileiro e mundial, enfocando o “crescimento” do turismo.

No Capítulo II é abordada a necessidade de se planejar estrategicamente e. São apresentados conceitos e informações sobre planejamento estratégico, fundamentais para garantir a sobrevivência no mercado competitivo de Brasília.

O Capítulo III pondera fatores importantes ao incremento do segmento, na Cidade.

A base das informações foram construídas com a pesquisa realizada nos hotéis do Plano Piloto, constituídas por dois questionários: o questionário Hotéis de Brasília I foi aplicado com todos os 42 hotéis, o outro questionário Hotéis de Brasília II aplicado com cinco hotéis quatro estrelas.

A expansão expressiva de sua rede hoteleira foi analisada por meio da coleta de informações junto às empresas envolvidas, considerando a oferta atual e para os próximos anos, cuja projeção baseia-se nos empreendimentos que estão sendo construídos e naqueles ainda em fase de projeto.

A conclusão aponta algumas perspectivas positivas para o crescimento da ocupação da rede hoteleira (hotéis “quatro estrelas” do Plano Piloto), caso essas estratégias sejam adotadas pelos Hotéis e pela cidade. 


\title{
CAPÍTULO 1
}

\section{MERCADO DO TURISMO}

\subsection{Conceitos}

Há várias definições de Turismo na literatura, em virtude da movimentação de pessoas de um lugar para outro e os dos impactos decorrentes desse deslocamento humano.

Pode-se citar a definição de Herman Von Schullard, em 1910:

\begin{abstract}
A soma das operações, principalmente de natureza econômica que estão diremente relacionadas com a entrada, permanência e permanência e deslocamento de estrangeiros para dentro e para fora de um país, cidade ou região ${ }^{1}$.
\end{abstract}

Por meio de uma análise etimológica, o termo "tour" denota o sentido de viagem em circuito, deslocamento de ida e volta (tour, em francês, significa apenas “movimento circular”, em linguagem figurada). Assim, por meio desse termo, os ingleses do século XVIII formaram o termo tourism, consolidado-se até os dias de hoje.

A Comissão de Estatística da Liga das Nações definiu, em 1937, o turista internacional como "a pessoa que visita um país que não seja o de sua residência por um período de, pelo menos, vinte e quatro horas”.

Em 1963, foi realizada em Roma a Conferência sobre Viagens Internacionais e Turismo, com o patrocínio das Nações Unidas, onde houve propostas para se distinguir os tipos de viajantes:

- Turistas - visitantes temporários que permanecem pelo menos vinte e quatro horas no país visitado, cuja finalidade da viagem envolve lazer, negócios, família, missões e conferências.

\footnotetext{
${ }^{1}$ OLIVEIRA, Antonio Pereira. Turismo e Desenvolvimento, Atlas, 2000, p. 31.
} 
- Excursionistas - visitantes temporários que permanecem menos de 24 horas no país visitado (incluindo viajantes de cruzeiros marítimos) ${ }^{2}$.

A Organização Mundial de Turismo - OMT aprovou essa definição em 1968 e, assim, começou a divulgá-la para que os países passassem a adotá-la .

O turismo destaca-se por meio de alguns segmentos de atuação, como se pode mencionar, por exemplo:

- Lazer, recreio e férias - lugares de interesse, compras, acontecimentos desportivos e culturais, esportes ativos amadores, alpinismo, cruzeiros, jogos de azar, acampamentos e lua-de-mel;

- Visita a parentes e amigos;

- Negócio ou motivos profissionais - instalações de equipamentos, inspeções, compras, vendas por conta de empresas estrangeiras, reuniões, conferência ou congressos, feiras comerciais e exposições, circuitos organizados pelos empregadores como prêmio, ministração de conferências ou concertos, organização de viagens turísticas, estabelecimento de contratos de alojamento e transportes, trabalhos como guias, participação em atividades desportivas, estudos, missão diplomática e cursos de idiomas;

- Tratamento de saúde - estações balneárias, SPAs e outros;

- Religião/peregrinação - participação em acontecimentos religiosos;

- outros - tripulação de aeronaves e de navios em serviços.

\subsection{Visão Mundial do Turismo}

O turismo consolida-se como uma atividade econômica que tem índices de crescimento e de desenvolvimento significativos, competindo ao lado de setores gigantes

\footnotetext{
${ }^{2}$ OLIVEIRA, Antônio Pereira, op. cit., p 34.
} 
como a informática e as telecomunicações. A indústria, que durante muitos anos se destacou no desempenho desse papel, perdeu seu lugar para a prestação de serviços, cujo setor de turismo tem as suas atividades concentradas.

A relação entre o turismo e a geração de empregos é bastante discutida e evidenciada entre os setores da economia, principalmente pelo seu poder de criar e expandir negócios, empregos diretos e um efeito multiplicador significativo para os empregos indiretos.

Estudos mostram que cada US\$ 7,000.00 de ingresso/ano gera um emprego ${ }^{3}$.

Dados da OMT - Organização Mundial de Turismo - mostram que são realizadas aproximadamente 600 milhões de viagens em todo o mundo, anualmente, sendo que $80 \%$ são de curta distância, e $20 \%$ são viagens com duração superior a 5 horas.

A Wold Travel \& Tourism Council tem previsões favoráveis para o mercado, pois indicam um crescimento de 4,7\% e a participação de 10,9\% do PIB mundial em 2001. A expectativa para este ano é a geração de 3,4 trilhões de dólares e aproximadamente 200 milhões de empregos ${ }^{4}$.

Para 2005 as previsões são de um faturamento global de US\$ 9 trilhões e US\$ 135 bilhões, na América Latina. Estima-se que o Brasil colabore com US\$ 6 bilhões dessa receita. Em 2001, a indústria do turismo gerou 265 milhões de empregos diretos e indiretos, e propiciou uma arrecadação mundial de impostos e taxas em torno de US\$ 654 bilhões. A previsões da OMT indicam que a indústria deverá absorver mais 144 milhões de pessoas até o ano de $2005^{5}$.

Para 2002 o WTTC apontou um crescimento nas receitas totalizando US\$ 4,2 trilhões, com 239 milhões de empregos ligados ao setor. Em 2010, o processo será evolutivo, atingindo o valor de US\$ 8 trilhões e de 328 milhões de empregos ${ }^{6}$.

Conforme demonstra a Tabela 1, pode-se traçar um panorama de crescimento entre 1989 e 2001. Em 2001, houve uma queda de 1,2\% na taxa de crescimento e nas receitas, entretanto essa estatística já tem previsões otimista para 2002, apesar da crise econômica mundial.

\footnotetext{
${ }^{3}$ World Travel \& Tourism Council - WTTC, Relatório Estatístico Mundial do Turismo, 2001

${ }^{4}$ Dimensionamento Econômico da Indústria de Eventos no Brasil, 2001/2002, p. 6-7.

${ }^{5}$ OLIVEIRA, Antônio Pereira, op. cit., p. 6.

${ }^{6}$ OLIVEIRA, Antônio Pereira, op. cit., p. 7.
} 
TABELA 1 - TURISMO MUNDIAL

\begin{tabular}{|c|c|c|c|c|}
\hline & & & RECEITAS & \\
\hline ANOS & $\begin{array}{c}\text { CHEGADAS } \\
\text { (milhões de } \\
\text { turistas) }\end{array}$ & $\begin{array}{c}\text { TAXA DE } \\
\text { CRESCIMENTO } \\
(\%)\end{array}$ & $\begin{array}{c}\text { (BILHÕES } \\
\text { DE } \\
\text { DÓLARE } \\
\text { S) }\end{array}$ & $\begin{array}{c}\text { TAXA ANUAL } \\
\text { DE } \\
\text { CRESCIMENTO } \\
(\%)\end{array}$ \\
\hline 1989 & 426,5 & 8,0 & 221,3 & 8,3 \\
\hline 1990 & 458,2 & 7,4 & 268,9 & 21,5 \\
\hline 1991 & 464,0 & 1,3 & 277,6 & 3,2 \\
\hline 1992 & 503,4 & 8,5 & 315,1 & 13,5 \\
\hline 1993 & 519,0 & 3,1 & 324,1 & 2,9 \\
\hline 1994 & 550,5 & 6,1 & 354,0 & 9,2 \\
\hline 1995 & 565,5 & 2,7 & 405,1 & 14,4 \\
\hline 1996 & 596,5 & 5,5 & 435,6 & 7,5 \\
\hline 1997 & 610,8 & 2,4 & 436,0 & 0,1 \\
\hline 1998 & 626,6 & 2,6 & 442,5 & 1,5 \\
\hline 1999 & 650,2 & 3,8 & 455,0 & 2,8 \\
\hline 2000 & 697,2 & 7,2 & 477,9 & 5,0 \\
\hline 2001 & 688,6 & $-1,2$ & 472,0 & $-1,2$ \\
\hline
\end{tabular}

Fonte: OMT, in: EMBRATUR, Anuário de Estatística , 2002.

Analisando o ranking da OMT, observa-se que, dos 40 destinos turísticos mais visitados pelos estrangeiros, o Brasil tem um grande potencial para elevar sua posição, por meio dos diversos atrativos que possui.

Nos rankings divulgados em 1990, 1995 e 1998, a França se manteve em primeiro lugar, e neste último ano, alcançou o número de 70 milhões de turistas.

Com relação à América do Sul, a Argentina obteve a posições 32, 30 e 28, em 1990. 1995 e 1998, respectivamente,e no último ano houve uma entrada de 4,8 milhões de estrangeiros. 
O Brasil conquistou as posições 53, 49 e 39 nos respectivos anos e, em 1998, recebeu 3,1 milhões de estrangeiros, elevando a sua posição no ranking e aumentando a sua participação no mercado de viagens internacionais.

Quando se parte para uma análise comparativa do ingresso de receitas financeiras, o Brasil manteve equilibrada a sua posição no ranking nos anos de 1990, 1995 e 1998, conquistado as posições 36.40 e 36, respectivamente, com um total de US\$ 2,8 bilhões no último ano.

É importante citar que mesmo a França estando posicionada à frente, com o maior número de turistas estrangeiros, os Estados Unidos chegaram ao primeiro lugar no ranking, com uma receita de US\$ 74,2 bilhões em 1998, superior ao dobro do que a França conseguiu contabilizar. Esses valores desconsideram as despesas com transporte.

\subsection{Análise do Turismo no Brasil}

Segundo a EMBRATUR - Instituto Brasileiro de Turismo ${ }^{7}$, o levantamento relativo a 2001 revela que 6 milhões de pessoas trabalham no setor (ou 9\% da força de trabalho), no Brasil, por meio de empregos diretos e indiretos. Esse mercado tem um faturamento anual de US\$ 4,5 bilhões (WTTC), o equivalente a 5,5\% do Produto Interno Bruto - PIB.

A TABELA 2 revela a evolução do mercado, no Brasil, com indicadores representativos de crescimento.

TABELA 2 - EVOLUÇÃO DO TURISMO NO BRASIL

\begin{tabular}{c|c|c}
\hline & $\begin{array}{c}\text { CHEGADA DE } \\
\text { TURISTAS } \\
\text { NO BRASIL } \\
\text { (em milhões de } \\
\text { turistas) }\end{array}$ & $\begin{array}{c}\text { RECEITA } \\
\text { (em U\$ } \\
\text { bilhões) }\end{array}$ \\
\hline $\mathbf{1 9 9 3}$ & 1,6 & 1,1 \\
1994 & 1,9 & 1,9
\end{tabular}

\footnotetext{
${ }^{7}$ Anuário Estatístico, 2002.
} 


\begin{tabular}{l|l|l}
1995 & 2,0 & 2,1 \\
1996 & 2,7 & 2,5 \\
1997 & 2,8 & 2,6 \\
1998 & 4,8 & 3,7 \\
1999 & 5,1 & 4,0 \\
2000 & 5,3 & 4,2 \\
2001 & 4,8 & 3,7 \\
2002 & 5,1 & \\
\hline
\end{tabular}

Os 130 países membros da OMT - Organização Mundial do Turismo, recebem a recomendação para que invistam, anualmente, o equivalente a $2 \%$ (dois por cento) das receitas cambiais turísticas em marketing no mercado externo, para incrementar o fluxo turístico existente e buscar novos nichos.

Conforme a TABELA 3, o Brasil ainda não atingiu esse percentual, pois precisaria aplicar US\$ 53 milhões ao ano, envolvendo um investimento mais agressivo na área.

Outra informação importante, e que reflete a força do turismo no cenário socioeconômico, indica que para cada US\$ 1.00 investido por um país, em marketing externo, é gerado US\$6.00 em ingresso de divisas.

TABELA 03 - EVOLUÇÃO DOS RECURSOS

PARA MARKETING E PROPAGANDA

NO ORÇAMENTO DA EMBRATUR (EM R\$)

\begin{tabular}{|c|c|c|}
\hline & RECURSOS & $\begin{array}{c}\text { RECURSOS } \\
\text { ORÇAMENTÁRIOS }\end{array}$ \\
\hline ANOS & $\begin{array}{c}\text { ORÇAMENTARIOS } \\
\text { DA EMBRATUR }\end{array}$ & $\begin{array}{c}\text { PARA PROMOÇÃO } \\
\text { DE MARKETING }\end{array}$ \\
\hline 1995 & $38.191 .000,00$ & $5.177 .301,00$ \\
\hline
\end{tabular}




\begin{tabular}{l|r|r}
1996 & $58.516 .000,00$ & $7.049 .966,00$ \\
1997 & $96.021 .000,00$ & $21.723 .676,00$ \\
1998 & $144.259 .000,00$ & $29.144 .671,00$ \\
1999 & $162.057 .000,00$ & $17.000 .000,00$ \\
2000 & $218.492 .387,00$ & $44.183 .593,00$ \\
\hline
\end{tabular}

Fonte: EMBRATUR, Evolução do Turismo no Brasil, 2000.

Com exceção do ano de 1999, o orçamento destinado à EMBRATUR (TABELA 3) no último ano cresceu, mas ainda não é o ideal para uma divulgação eficaz que atraia turistas para o Brasil.

O comportamento do fluxo de turistas no mercado brasileiro tem sido levantado e analisado pela EMBRATUR por meio da realização de uma pesquisa anual para identificar o perfil do turista estrangeiro, apontando um histórico de crescimento e os motivos envolvidos (TABELA 4).

Na TABELA 4, é relevante observar o percentual das viagens motivadas pelos negócios e eventos no período de 1993 a 2001. É possível ver também que nos últimos três anos o turismo de negócios e eventos totalizou, em média, 29\% (vinte e nove por cento) dos motivos de viagem. Isso mostra, portanto, o crescimento da área num intervalo de oito anos, onde se percebe uma tendência do mercado em alavancar o setor.

TABELA 4 - MOTIVO DAS VIAGENS DE ESTRANGEIROS PARA O BRASIL (EM \%)

\begin{tabular}{l|c|c|c|c|c|c|c|c|c}
\hline \multirow{2}{*}{$\begin{array}{c}\text { MOTIVO } \\
\text { DA } \\
\text { VIAGEM }\end{array}$} & \multicolumn{10}{|c}{ ANO } \\
\cline { 2 - 9 } & $\mathbf{1 9 9 3}$ & $\mathbf{1 9 9 4}$ & $\mathbf{1 9 9 5}$ & $\mathbf{1 9 9 6}$ & $\mathbf{1 9 9 7}$ & $\mathbf{1 9 9 8}$ & $\mathbf{1 9 9 9}$ & $\mathbf{2 0 0 0}$ & $\mathbf{2 0 0 1}$ \\
\hline Turismo & 75,3 & 76,3 & 69,5 & 67,2 & 65,3 & 71,8 & 77,6 & 57,0 & 55,5 \\
Negócios & 18 & 19,4 & 22 & 24,6 & 28,3 & 18,1 & 18,1 & 23,4 & 24,3 \\
Cong/Conv & 3,8 & 2,9 & 4,9 & 4,1 & 4,3 & 3,2 & 3,2 & 4,5 & 5,9
\end{tabular}




\section{\begin{tabular}{l|l|l|l|l|l|l|l|l|l} 
& & & & & & \\
Outros & 2,9 & 1,4 & 3,6 & 4,1 & 2,1 & 1,1 & 1,1 & $15,1 *$ & 14,3 \\
\hline
\end{tabular}}

Fonte: EMBRATUR, Estudo da Demanda Turística Internacional, 2001.

* A partir de 2000, incluem-se em outros motivos as visitas de familiares/amigos, tratamento de saúde, estudos e atividades religiosas.

Por sua vez, o que se observa é que, no tocante às insatisfações de turistas estrangeiros, constata-se através da TABELA 5 o registro principal quanto à precariedade das informações e sinalizações turísticas, cuja análise se defronta com os índices de 30,25\%, seguidos de $12,75 \%$ para segurança pública e de 12,54\% para limpeza pública, isso no período de 1993 a 2001.

TABELA 5 - INSATISFAÇÃO DOS TURISTAS ESTRANGEIROS (EM \%)

\begin{tabular}{|c|c|c|c|c|c|c|c|c|c|}
\hline \multirow{2}{*}{$\begin{array}{l}\text { ITENS MAIS } \\
\text { CRITICADOS }\end{array}$} & \multicolumn{9}{|c|}{ ANO } \\
\hline & 1993 & 1994 & 1995 & 1996 & 1997 & 1998 & 1999 & 2000 & 2001 \\
\hline $\begin{array}{l}\text { Limpeza } \\
\text { Pública }\end{array}$ & 18,1 & 18,2 & 21,8 & 19,1 & 19,2 & 14,4 & 13,8 & 9,5 & 12,54 \\
\hline $\begin{array}{l}\text { Segurança } \\
\text { Pública }\end{array}$ & 17 & 16,6 & 16,1 & 13,1 & 13,1 & 9,8 & 10,2 & 9,3 & 12,75 \\
\hline $\begin{array}{l}\text { Sinalização } \\
\text { Turística }\end{array}$ & 18,5 & 23,9 & 22,3 & 19,4 & 21,7 & 12,3 & 12,0 & 11,1 & 15,78 \\
\hline Táxis & 16,1 & 16,2 & 16,5 & 11,3 & 11,8 & 6,4 & 5,9 & 4,8 & 5,82 \\
\hline $\begin{array}{l}\text { Transporte } \\
\text { Urbano }\end{array}$ & 8,7 & 11,2 & 13,5 & 12 & 13,5 & 5,6 & 9,5 & 10,2 & 7,71 \\
\hline $\begin{array}{l}\text { Guias de } \\
\text { Turismo } \\
\text { Informação }\end{array}$ & 5,7 & 8,3 & 8,1 & 9,9 & 10,4 & 5,9 & 12,2 & 14,54 & 7,74 \\
\hline Turística & 9,1 & 9,3 & 16,3 & 10,3 & 13,3 & 9,5 & 20,2 & 21,96 & 19,42 \\
\hline
\end{tabular}

Fonte: EMBRATUR, Estudo da Demanda Turística Internacional, 2001.

Com tantas insatisfações, faz-se necessário que o Brasil reavalie as suas infraestruturas e pratique melhor os cinco pilares básicos do Turismo, que são: cama, caminho, compras, comida e carinho, em que cada qual exige uma organização, um equipamento e um tratamento específico. 


\section{CAPÍTULO 2}

\section{PLANEJAMENTO ESTRATÉGICO}

2.1 Considerações Sobre Meios de Hospedagem e Empresa Hoteleira 
A EMBRATUR considera meio de hospedagem o estabelecimento licenciado pela autoridades competentes para prestar serviços de hospedagem, regulamentado ainda, que estes devem oferecer aos hóspedes, no mínimo, alojamento, serviços de portaria e recepção, serviços de alimentação, circulação, lazer e uso comum e outros serviços de conveniência do hóspede. Ou seja, um meio de hospedagem precisa oferecer serviços básicos que devem ser observados com extrema atenção por parte dos proprietários de hotéis, principalmente aqueles que se encontram em quadro de declino de taxa de ocupação.

Segundo o Regulamento dos Meios de Hospedagem ${ }^{\mathbf{8}}$, são os seguintes os tipos básicos de meios de hospedagem de turismo:

\section{HOTEL:}

Tipo convencional, normalmente localizado em perímetro urbano e destinado a atender turistas de lazer ou negócio.

\section{HOTEL HISTÓRICO:}

Instalado total ou parcialmente em edificação de valor histórico ou de significado regional; normalmente sujeito a restrições de natureza construtiva ou arquitetônica.

\section{HOTEL DE LAZER:}

Localizado fora dos centros urbanos, com áreas não edificadas amplas e com aspectos arquitetônicos e construtivos, instalações, equipamentos e serviços destinados a recreação e ao entretenimento.

\section{POUSADA:}

Meio de hospedagem mais simplificado e normalmente limitado ao necessário à hospedagem.

O resort inclui-se em hotel de lazer, subordinado às seguintes condições:

Localização em área de conservação ou equilíbrio ambiental

Ter sido antecedido por estudos de impacto ambiental e de planejamento de ocupação do uso do solo 
Ter área total e não edificada, bem como infra-estruturas de entretenimento e lazer bastante superiores a empreendimentos similares.

\subsubsection{Classificação dos Hotéis}

Ainda pela normatização da EMBRATUR, os meios de hospedagem podem ser classificar:

\begin{tabular}{llcccc} 
CATEGORIA & SÍMBOLO & \multicolumn{4}{c}{ TIPOS DE MEIOS DE HOSPEDAGEM } \\
Luxo superior & $* * * * *$ & & $\mathrm{H}$ & $\mathrm{HL}$ & $\mathrm{HH}$ \\
Luxo & $* * * *$ & $\mathrm{H}$ & $\mathrm{HL}$ & $\mathrm{HH}$ & \\
Standard superior & $* * *$ & $\mathrm{H}$ & $\mathrm{HL}$ & $\mathrm{HH}$ & $\mathrm{P}$ \\
Standard & $* *$ & $\mathrm{H}$ & $\mathrm{HL}$ & $\mathrm{HH}$ & $\mathrm{P}$ \\
Simples & $*$ & $\mathrm{H}$ & $\mathrm{HL}$ & $\mathrm{HH}$ & $\mathrm{P}$
\end{tabular}

\subsection{Estratégia de Serviços}

Para o hotel oferecer um serviço de excelente qualidade, é necessário que desenvolva uma estratégia de serviços que pretenda, como a teoria de Castelli, "Segmentar os clientes de acordo com as suas expectativas em relação aos serviços, descobrir quais são exatamente essas expectativas e ajudá-las de modo que correspondam a sua capacidade de oferecer serviços”.9.

Para Kotler \& Armstrong ${ }^{\mathbf{1 0}}$, o planejamento estratégico é “O processo de desenvolver e manter um ajuste estratégico entre os objetivos e potencialidades da empresa e as mudanças de suas oportunidades de mercado. Conta com o desenvolvimento de uma missão clara para a empresa, definição dos objetivos, um bom portfólio de negócios e coordenação das estratégias funcionais”.

Já para Kuazaqui (2000) o planejamento estratégico “Consiste na criação de valores e condições que possibilitem à empresa optar por ações diante de oportunidades e ameaças, pontos fracos e fortes, otimizando as relações e vantagens competitivas em relação ao ambiente ou setores envolvidos"•

O conceito de estratégia nasceu da necessidade de se atingir objetivos em situações de concorrência, como é o caso na guerra, nos jogos, e nos negócios. A estratégia como arte, envolve

\footnotetext{
${ }^{9}$ CASTELLI, Geraldo, Administração Hoteleira, 2001.p.143.

${ }^{10}$ KOTLER \& ARMSTRONG,
} 
certa conotação de astúcia, de tentativa de enganar ou superar o concorrente com a aplicação de algum procedimento inesperado, que provoca ilusão ou que o faz agir como não deveria, mas segundo o interesse do estrategista.

Já em administração, cujo sentido científico não anula a arte, a utilização do termo estratégia está associada à formulação de diretrizes e ao planejamento das organizações.

\subsection{Planejamento Estratégico}

O Planejamento Estratégico, entendemos, é a base de qualquer pesquisa e/ou projeto. Nesse sentido, apresentaremos doravante os seus conceitos, princípios, filosofias, partes e tipos, bem como os aspectos da teoria, os quais facilitarão o enquadramento da empresa como um todo, perante seus fatores externos e internos.

Esse enquadramento de interação dos fatores externos e internos dos hotéis a consolida a abordagem estratégica nos hotéis.

O sucesso administrativo é algo que provém de mudança, eis que “Os administradores bem sucedidos antecipam mudanças, exploram as oportunidades, corrigem o mau desempenho, conduzindo a organização para seus objetivos”. (STEPHEN \& ROBBINS, 1978)

\subsubsection{O Processo de Planejamento}

O processo de planejamento pode ser subdividido em cinco etapas:

- diagnóstico

- estabelecimento de objetivos

- seleção de estratégias e meios

- planos de trabalho

- controle 


\section{Diagnóstico}

É a etapa na qual se analisa a situação existente. A qualidade do processo de planejamento, como um todo, nasce nesta fase. Um bom diagnóstico é a base do planejamento. Será denominado de Análise macroambiental.

\section{Estabelecimento de Objetivos}

É a determinação da situação planejada para o futuro. É uma meta a se atingir. Os objetivos são o ponto de convergência de toda a organização.

\section{Seleção de Estratégias e Meios}

Após analisada a situação presente e determinados os objetivos, a etapa seguinte é a escolha de estratégias e a definição dos meios necessários.

\section{Planos de Trabalho}

São as ações necessárias para que os objetivos sejam alcançados. Situam-se nos planejamentos tático e operacional e observam estratégias e meios escolhidos. Serão denominados de Planos setoriais.

\section{Controle}

Fase de acompanhamento do processo e ações corretivas, quando necessárias. Reúne base de dados e os indicadores da empresa e de mercado. Será um dos programas de trabalho dos Planos setoriais.

FIGURA 1: PROCESSO DE PLANEJAMENTO - ESQUEMA BÁSICO

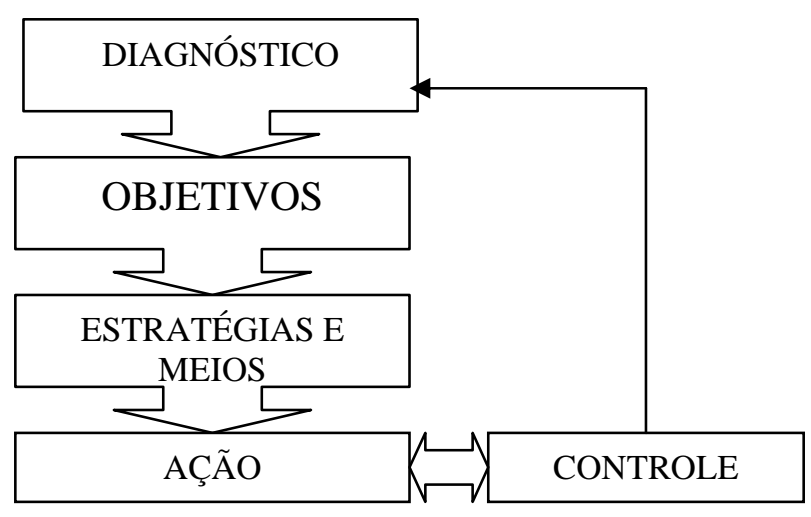

O roteiro básico pode ainda ser observado sob dois enfoques:

- fase de estudos 
- fase de ações, com base nos estudos

A fase de estudos é aquela que reúne o diagnóstico, com todos os levantamentos, pesquisas e análises sobre a situação presente, o estabelecimento de objetivos e a seleção de estratégias e escolha de meios e instrumentos para alcançá-los.

A fase de ações abriga os planos de trabalho. São os planos táticos e operacionais que vão transformar os estudos em medidas concretas, as quais objetivarão as transformações desejadas.

\subsubsection{Análise Macroambiental}

Representa a elaboração do diagnóstico. O conhecimento da situação atual é realizado através da Análise macroambienta1.

A análise é composta de duas partes: análise do ambiente externo e análise do ambiente interno do hotel. Na análise macroambiental externa, surgirão aspectos positivos e aspectos negativos. Eles serão grupados separadamente. Os aspectos positivos serão reunidos sob o título de oportunidades. Os aspectos negativos constituirão a lista das ameaças. Por sua vez, a análise macroambiental interna igualmente revelará aspectos positivos e aspectos negativos. Os aspectos positivos constituirão a lista dos pontos fortes e a lista dos aspectos negativos terá o título de pontos fracos .

\subsubsection{Análise Macroambiental Externa}

Tem como objetivo estudar todos os fatores externos à organização. Estuda as forças da sociedade que afetam o hotel e todos os demais aspectos externos à organização. A análise macroambiental externa pode se orientar por alguns parâmetros, conforme a Tabela a seguir.

\section{TABELA 6 - ANÁLISE MACROAMBIENTAL EXTERNA}

\section{ECONOMIA}

DEMOGRAFIA

Renda e sua distribuição, preços, emprego, dinamismo econômico, padrões de consumo etc.

População, número de habitantes, composição, distribuição, 


\begin{tabular}{|c|c|}
\hline & | escolaridade, faixa etária, etc. \\
\hline POLÍTICA & Legislação, regulamentações, movimentos populares, etc. \\
\hline TECNOLOGIA & $\begin{array}{l}\text { Tecnologias de produto, sistemas informatizados, prestação de } \\
\text { serviços, comunicação, internet, etc. }\end{array}$ \\
\hline MEIO AMBIENTE & Meio urbano e meio natural \\
\hline SISTEMA DE TURISMO & $\begin{array}{l}\text { Estilos de vida, valores da sociedade, cultura popular etc. } \\
\text { Atrativos, infra-estrutura, competitividade, cultura associativa, } \\
\text { desenvolvimento empresarial, marketing, conscientização da } \\
\text { população para o turismo, atuação do setor público, etc. }\end{array}$ \\
\hline MERCADO & $\begin{array}{l}\text { Fluxos turísticos existentes, mercado potencial, segmentação, } \\
\text { modalidades de turismo, estudos e pesquisas, base de dados }\end{array}$ \\
\hline CONCORRÊNCIA & $\begin{array}{l}\text { Análises quantitativa e qualitativa, recursos de marketing, tendências, } \\
\text { inovações }\end{array}$ \\
\hline
\end{tabular}

Recomenda-se estudar ameaças e oportunidades com o envolvimento do maior número possível de pessoas. Deve ser usada a técnica do brainstorming ${ }^{11}$. Os estudos em grupo enriquecem as propostas de planejamento. Os estudos de mercado são subsidiados por especialistas.

\subsubsection{Mercado}

Os estudos de mercado orientam os investimentos, as estratégias de marketing e as ações para o atendimento ao cliente. Em função do mercado, o hotel articula sua interface com o meio e programa ações internas. Somente as pesquisas dirão quais são as tendências desse mercado. Portanto, com relação aos clientes, tem-se que saber quais os seus desejos, quem são os atuais, os locais de origem, meios de transporte usados, faixa etária, renda, atrativos turísticos preferidos, etc.

Cabe também estudar quais mercados podem ser alcançados e em que segmentos. As oportunidades de atrair hóspedes são compartilhadas com o destino turístico como um todo. Por isso, as pesquisas de mercado, sob o ponto de vista do hotel e sob o ponto de vista

\footnotetext{
${ }^{11}$ Técnica de debate livre em que os participantes (de reunião, conferências, etc.) dão idéias e sugestões
} 
do núcleo turístico, são uma etapa essencial da análise macroambiental externa, dentro do processo de planejamento estratégico.

Dessa maneira, a análise externa deve contemplar, entre outros aspectos :

- mercado atual e mercado potencial do hotel

- mercado atual e mercado potencial do destino (sistema de turismo)

- fornecedores, trade turístico, concorrentes

- clientes (em todos os seus segmentos, regiões, parcelas de mercado etc.)

- sistema financeiro, mercado de trabalho, sindicatos

- entidades de ensino e pesquisa, regulamentações governamentais

- comércio exterior, economia internacional

- meio ambiente

- público (em função da imagem e atitudes da empresa)

- imprensa em seus diversos segmentos.

\subsubsection{Oportunidades e Ameaças}

São duas listas distintas de fatores externos que influenciam a organização, os quais se tornam incontroláveis na instituição, ou seja, por exemplo, a situação econômica do país, tendências do mercado nacional e internacional do turismo, regulamentação de vôos, desequilíbrio na distribuição de renda, qualidade dos serviços públicos na região, marketing do destino turístico,onde o hotel está inserido, cultura empresarial do local, índices de criminalidade, etc.

O objetivo é consolidar um painel de oportunidades de negócios e outro de ameaças. As estratégias e os programas de trabalho visarão explorar as oportunidades e os pontos fortes e atenuar os efeitos das ameaças e dos pontos fracos. Essa análise deve ser refeita periodicamente, pois através da mesma é possível acompanhar a evolução dos pontos fortes e fracos. O monitoramento permanente do meio é a base da gestão estratégica da hotelaria.

Uma alternativa para elaboração dessa análise é subdividi-la por temas ou focos. Como a seguir: 


\begin{tabular}{l|c|c}
\hline Oportunidades & Foco & Ameaças \\
\hline & Concorrência & \\
& Infra-Estrutura Urbana & \\
& Sistema de Turismo & \\
& Economia Regional & \\
& Ações Governamentais & \\
\hline
\end{tabular}

\subsubsection{Análise Macroambiental Interna}

Trata-se de uma análise das condições internas da organização. Reúne todos os fatores que estão ao alcance do administrador hoteleiro. A análise macroambiental interna pode orientar-se por alguns parâmetros, conforme a Tabela a seguir.

\section{TABELA 08 - ANÁLISE MACROAMBIENTAL INTERNA}

\section{RECURSOS FINANCEIROS}

RECURSOS HUMANOS

RECURSOS DE CAPITAL

MÉTODOS DE TRABALHO

TECNOLOGIA

INSTRUMENTOS DE

MARKETING

CULTURA

ORGANIZACIONAL

PRESERVAÇÃO

AMBIENTAL

RESPONSABILIDADE SOCIAL
Receitas, fluxo de caixa, orçamentos, fontes de recursos, custos praticados, rentabilidade, valor patrimonial, tarifas etc.

Dimensionamento, qualificação, desenvolvimento, nível de satisfação dos empregados, prevenção de acidentes etc.

Instalações e equipamentos, nível de atualização tecnológica, informatização

Divisão do trabalho, atribuição de autoridade, processos de trabalho, produtividade e qualidade, controles, atendimento ao mercado, padronização de rotinas, etc.

Atualização tecnológica. utilização de sistemas de informática, internet, televisão a cabo e outros recursos

Missão, objetivos e metas, estratégias de marketing, planos setoriais, promoção, informações etc.

Valores compartilhados pelas pessoas que contribuem para o sucesso da organização; atitudes

Respeito ao meio urbano e ao meio natural. uso racional de água, energia elétrica e disposição de resíduos, entre outros

Inserção do hotel nos esforços de desenvolvimento social da comunidade onde inserida; recolhimento de impostos; respeito às leis.

\subsubsection{Pontos Fortes e Pontos Fracos}

São analisados os fatores gerenciáveis, internos à organização hoteleira. Verificase a situação das construções, equipamentos, finanças, tecnologia, taxas de ocupação, políticas de preços, métodos de trabalho, marketing e recursos humanos em geral, destacando, como sugestão:

- valores da organização

- integridade das instalações físicas 
- situação dos equipamentos e sistemas de manutenção

- situação econômico financeira

- situação do mobiliário e utensílios; atualização; estoques praticados

- métodos de trabalho

- tecnologia da informação; atualização tecnológica de equipamentos

- gestão de recursos humanos

- nível de satisfação dos clientes

- envolvimento social e compromissos com a sustentabilidade ecológica

- imagem junto à comunidade

- imagem junto aos mercados intermediário e final

- taxas de ocupação das Uhs (Unid. Habitacionais), sazonalidade, tarifas médias

- atuação diversificada dirigida a eventos

- situação de alimentos e bebidas

- ações em marketing, telefonia

- sistema de reservas, entre outros

A importância desse levantamento é, igualmente, ter um conhecimento da situação da empresa hoteleira, que venha a orientar os programas de trabalho necessários. Os programas terão como objetivo minimizar ou eliminar os pontos fracos e potencializar os pontos fortes. Da mesma forma que a Análise externa, a Análise interna deve ser apresentada como uma tabela de duas colunas, conforme a seguir:

TABELA 9 - EXEMPLO DE ANÁLISE MACROAMBIENTAL INTERNA

\begin{tabular}{l|l|l}
\hline PONTOS FORTES & \multicolumn{1}{|c}{ FOCO } & PONTOS FRACOS \\
\hline & $\begin{array}{l}\text { Situação financeira } \\
\text { Taxas de ocupação } \\
\text { Marketing }\end{array}$ & \\
Recursos humanos & \\
Tecnologia & \\
& Governança & \\
Recepção & \\
Alimentos e bebidas & Reservas & \\
& Manutenção predial e & \\
& equipamento, Compras & \\
& Etc. & \\
\hline
\end{tabular}

A análise macroambiental oferece um painel de aspectos positivos e negativos. A lógica do processo de planejamento é simples: eliminar ou atenuar os aspectos negativos e potencializar os aspectos positivos. No transcorrer do tempo o processo de planejamento 
começa a produzir resultados, pela eliminação sistemática de deficiências e pelo simultâneo aproveitamento de suas vantagens e pontos fortes.

\subsubsection{Objetivos do Planejamento Estratégico}

Os propósitos do planejamento são refletidos pela situação futura que se deseja alcançar. Sua dimensão, seus produtos. Como o hotel deseja ser visto. Onde quer chegar. Alguns autores recomendam o estabelecimento dos objetivos de forma bastante simples. Outros indicam um objetivo central e outros, derivados. Empresas de maior porte conceituam os propósitos através da formulação de uma visão de futuro, da declaração de missão da organização, e expressam, ainda, os objetivos e metas a ser alcançados.

- Conceito de Visão de Futuro - como a organização se vê no futuro; onde ela quer chegar.

- Conceito de Missão - define a filosofia de negócios; justifica a razão de sua existência.

- Objetivos - resultados concretos que a empresa espera alcançar ao longo de determinado período de tempo; recomenda-se uma redação simples e a explicitação de indicadores quantificáveis.

Muitas vezes essas conceituações causam uma certa confusão, por exemplo, entre objetivos e metas. O exercício do planejamento, entretanto, deve buscar simplicidade e clareza na metodologia adotada, dentro de limites razoáveis. O que importa, efetivamente, é a visualização do futuro que se deseja para o projeto ou empreendimento estudado.

A partir daí os objetivos do processo de planejamento devem ser expressos com simplicidade e redigidos com toda clareza. Deve-se facilitar a compreensão de onde se deseja chegar para todos os que compõem a equipe de trabalho, para os parceiros e fornecedores.

O planejamento deve ser um traço de união dentro da empresa. Os estudos de planejamento podem ser subdivididos entre as áreas mais importantes para a organização, inclusive estabelecendo objetivos para cada uma delas. O planejamento pode partir para o estabelecimento de múltiplos objetivos, desde que mantidas coerência, harmonia e prevalência dos propósitos de longo prazo da organização hoteleira. 
As áreas de atuação que poderiam sugerir objetivos de longo prazo seriam:

- desempenho operacional

- desempenho econômico financeiro

- imagem perante a sociedade

- relacionamento com os acionistas ou investidores

- relacionamento com o quadro de pessoal

Os objetivos podem ser estabelecidos em todas essas áreas, como foi dito, com a formulação de um objetivo de longo prazo que paire sobre os demais, ou ainda, objetivos em cada uma das áreas, com uma visão de futuro que os interligue e assegure uma convergência de esforços.

Alguns objetivos poderiam ser considerados para a hotelaria, como por exemplo:

- procurar manter a taxa de ocupação hoteleira: pelo menos em nível compatível com as necessidades de resultados financeiros mínimos pretendidos

- buscar ampliar a taxa de ocupação hoteleira

- ampliar a participação em determinados segmentos de mercado visando incrementar a eficiência relativa da organização, ou conquistar novos segmentos de mercado

- lançar produtos que possam ser agregados à hotelaria

- evitar ou atenuar as flutuações sazonais ou cíclicas nas taxas de ocupação e nos lucros (sazonalidades causam ineficiência de fora para dentro e representam, ainda, perda de posição relativamente à concorrência)

- aumentar os lucros (inclusive como forma de prover recursos para reinvestimentos)

- ampliar lucros por ação, em casos de sociedades anônimas (como forma de atração de capitais) 


\section{CAPÍTULO 3}

\section{POTENCIALIDADE DE BRASÍLIA PARA O TURISMO}

\subsection{História de Brasília}

Inaugurada em 21 de abril de 1960, o que poucos sabem é que a sua construção teve duração recorde: três anos e 10 meses. No entanto, desde a sua concepção passaram-se mais de 190 anos. A idéia de fixar o governo no centro do Brasil já existia desde 1810. Localizada em um ponto estratégico, a capital federal deveria ficar longe de portos e de possíveis áreas de fácil acesso para os invasores.

O artigo $3^{\circ}$ da Constituição Federal de 1891 determinava uma área de 14 mil quilômetros quadrados para o surgimento da nova capital, em meio ao Planalto Central. A esta área foi enviada uma expedição integrada por vários cientistas, que entregaram um relatório exato com todas as informações sobre a região, em 1894.

O início da construção de Brasília, todavia, só veio a acontecer anos mais tarde, por idealismo e iniciativa do então Presidente da República, Juscelino Kubitschek. Projetada pelo grande urbanista Lúcio Costa, vista de cima tem a forma de um avião.

Brasília nasceu com o seu destino profetizado por Dom Bosco, que, no século XIX, já havia dito que surgiria uma nova civilização entre os paralelos $15^{\circ}$ e $20^{\circ}$. Assim, foi inevitável a criação de várias lendas em torno dessa que é considerada um oásis em meio ao deserto. Histórias de discos voadores, capital do País do futuro, local propício para pouso de naves extraterrestres, entre outras, fizeram com que Brasília se tornasse a mãe acolhedora de muitas seitas e religiões.

Devido ao seu desenvolvimento econômico, cidades dormitórios foram sendo criadas ao seu redor, batizadas de satélites. Sua importância já rompeu barreiras. Desde 1987, Brasília é reconhecida pela Unesco como Patrimônio Histórico e Universal da Humanidade ${ }^{12}$.

\footnotetext{
${ }^{12}$ Revista Brasília Capital do Século 21, ADETUR, 2000, p 15.
} 
A origem do nome Brasília, ao contrário da cidade, que é considerada nova, é de longa data. Esse nome foi sugerido, em 1823, por José Bonifácio, em um memorial encaminhado à Assembléia Geral Constituinte do Império.

Brasília chega aos 43 anos consolidada como capital da República e assumindo ares de grande metrópole. A cidade tem 2.043.169 de habitantes. Desse número, a maioria é composta por mulheres. Seu clima é tropical de savana e temperado chuvoso, com temperatura média anual de $20,5^{\circ} \mathrm{C}$.

Tamanho crescimento leva à reflexão, cada vez maior, sobre as alternativas de desenvolvimento da região. É fundamental incrementar os diversos segmentos da economia (comércio, serviços, indústria, agro-business) como forma de gerar emprego e renda para as novas gerações.

É nesse contexto que surge o turismo como uma das maiores vocações da Capital Federal. Em Brasília, a condição de capital da República a torna, naturalmente, uma referência para milhões de brasileiros. Quem não gostaria de conhecer os monumentos cívicos, o traço urbanístico de Lúcio Costa, as formas curvilíneas da arquitetura de Niemeyer?

3.2 O Turismo em Brasília

O empresariado de Brasília é consciente da importância do turismo como elemento de grande impacto na geração de emprego, renda e impostos em sua economia.

O turista encontra na cidade uma ampla e moderna estrutura de serviços a seu dispor. Brasília possui o terceiro parque hoteleiro do País, com disponibilidade de 8.907 UHs, totalizando 17.981 leitos, com previsões de expansão, até o final de 2004, para 25.000 leitos.

O aeroporto de Brasília é o terceiro em movimento de passageiros no País, com ligação com todas as capitais brasileiras diariamente, com 96 vôos diários regulares, mais 
76 vôos particulares e taxi aéreo por dia, totalizando 4.596.617 embarques e desembarques, em 2002, e 5.267.466, em 2003, segundo estudo da Infraero. ${ }^{13}$

Outro fator que Brasília apresenta e, por ser uma cidade com atrações cívicas, onde a vinda do turista a negócio ou em eventos pode motivá-los a trazer seus familiares, pois enquanto participa do negócio ou eventos, ele conhece a capital do seu País. Após o termino dos eventos, ele e sua família podem desfrutar das atrações da cidade e do entorno.

Os restaurantes apresentam amplo cardápio de opções de cozinha nacional e internacional, que não ficam nada a dever aos grandes centros urbanos do País.

O turismo receptivo brasiliense conta, ainda, com inúmeras agências de viagens, locadoras de veículos, serviços de radio táxis, museus, bares, boates, templos religiosos, casas de câmbio, shoppings centers, inúmeras atrações naturais e turísticas, bibliotecas, cinemas, monumentos, palácios, parques e jardins, teatros e outras atrações.

A TABELA 10 apresenta uma evolução crescente no percentual de turistas brasileiros com destino a Brasília, em que os motivos de negócios e eventos totalizam 79,9\%, em 2002, 76,1\%, em 2001, e 77,3\%, em 2000. Com isso, vê-se que Brasília é uma cidade voltada para o turismo de negócios e eventos.

Outro aspecto que chama a atenção dos interessados é a redução do percentual de turistas que visitam Brasília com o intuito que não seja negócios ou eventos.

TABELA 10 - PERFIL ANUAL DO TURISTA BRASILEIRO NOS HOTÉIS DE BRASÍLIA

\begin{tabular}{l|c|c|c}
\hline MOTIVOS & $\mathbf{2 0 0 0}$ & $\mathbf{2 0 0 1}$ & $\mathbf{2 0 0 2}$ \\
\hline Negócios & $\mathbf{6 3 , 0}$ & $\mathbf{6 4 , 4}$ & $\mathbf{6 5 , 8}$ \\
Congressos / Convenções & $\mathbf{1 4 , 3}$ & $\mathbf{1 1 , 7}$ & $\mathbf{1 4 , 1}$ \\
Turismo & 4,6 & 5,7 & 4,4 \\
Outros & 18,1 & 18,3 & 15,7 \\
Permanência média (dias) & 2,1 & 2,2 & 2,7 \\
\hline
\end{tabular}

Fonte: ADTUR - Agência de Desenvolvimento do Turismo do DF, conforme fichas nacionais de registros de hóspedes - FNRH'S.

${ }^{13}$ Informe Infraero 2003, Empresa Brasileira de Infra-Estrutura Aeroportuária - INFRAERO 
A vinda de turista em Brasília também não e muito diferente. 61,1\%, em 2002, vieram com o objetivo de participar de negócios ou eventos; 52,9\%, em 2001, e 50,0\%, em 2000 (Tabela 13).

TABELA 11- PERFIL ANUAL DO TURISTA ESTRANGEIRO NOS HOTÉIS DE BRASÍLIA

\begin{tabular}{l|c|c|c}
\hline MOTIVOS & $\mathbf{2 0 0 0}$ & $\mathbf{2 0 0 1}$ & $\mathbf{2 0 0 2}$ \\
\hline Negócios & 41,8 & 43,6 & 44,4 \\
Congressos / Convenções & 8,2 & 9,3 & 16,7 \\
Turismo & 30,1 & 33,1 & 28,9 \\
Outros & 19,9 & 14,4 & 10,0 \\
Permanência média (dias) & 2,0 & 2,0 & 2,3 \\
\hline
\end{tabular}

Fonte: ADTUR - Agência de Desenvolvimento do Turismo do DF, conforme fichas nacionais de registros de hóspedes - FNRH'S.

Já com relação ao Turismo: Brasília oferece o turismo de negócio e o cívico. A partir das Fichas de Registros de Hóspedes dos 47 Hotéis de Brasília , localizados no Plano Piloto.

Este Estudo nos oferece uma indicação de que o visitante de Brasília, na maioria são homens de faixa etária dos 40 anos, de classe média alta e sua permanência na cidade é curta, média de 2,8 dia.

O perfil do turista de Brasília é, em regra: do sexo masculino, casado, com idade entre 20 e 50 anos, com escolaridade nível superior, renda média mensal acima de R\$ 3.001,00, residentes na Região Sudoeste e que tem em Brasília, interesse na área de negócios, político e participações em eventos. Mais da metade dos visitantes que vêm à Brasília (57\%) transportam-se de avião.

\section{GRÁFICO 1 - LOCAL DE HOSPEDAGEM DOS TURISTAS DE BRASÍLIA}

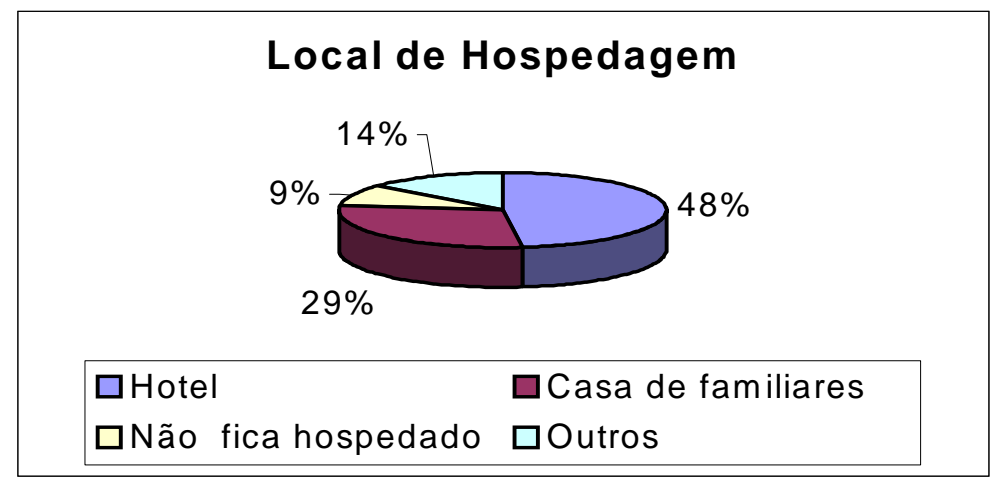

Fonte: Pesquisa FBC\&VB/SEBRAE/CTI, 2001 (I Dimensionamento Econômico da Indústria de Eventos no Brasil - 2001/2002). 
Como mostrado nas TABELAS 13 e 14, com relação à ocupação média dos últimos três anos, houve uma queda de $5 \%$ na ocupação dos hotéis, levando-se em consideração a entrada de novos hotéis na cidade.

Vale ressaltar que os eventos e negócios na cidade de Brasília são responsáveis por mais de $76 \%$ da ocupação dos hotéis. Com essa estatística, a rede hoteleira tem grande potencial para aumentar as suas receitas em até $40 \%$, mediante a sazonalidade de suas Uhs. O Turismo Cidadão aponta como uma das grandes alternativas econômicas no Distrito Federal, o turismo cívico tende a crescer. Conhecer o funcionamento dos poderes do país e seus órgão e um grande passo para a área educacional, que despertem o civismo e patriotismo em crianças e jovens.

Não esquecendo também que o turismo místico e religioso, no qual a capital federal é também a capital espiritual. Brasília abriga todas as fés e religiões, cercada de misticismo. Neste contexto, a cidade possui o tour da Terra Promedida, que consiste em visitações a locais com Erminda Dom Bosco, a Catedral, o Templo Budista, o Templo da Boa Vontade e outros. Existe ainda o roteiro do entorno como o Vale do Amanhecer e a Cidade Eclética.

O turismo rural e ecológico tem tido também uma grande representatividade, pois seu crescimento e conquista tem sido uma das molas propulsoras para atrair pessoas não somente da cidade mas dos outros estados e pais.

Dados preliminares das pesquisas realizadas pelo Convention \& Visitors Bureau apontam que a cidade de Brasília está perdendo $\mathrm{R} \$ 2$ bilhões por ano, devido ao esgotamento e falta de espaço físico para a promoção de médio e grande feiras e eventos de modo geral.

Outros dados apontados pela pesquisa perfil do turista do Distrito Federal 2001 realizada pelo Brasília Convention \& Visitors Bureou, revelam que a receita total estimada de turismo (gastos com pernoites, restaurantes, entretenimento, compras e transportes), na cidade, foi de R\$ 1,6 bilhões, em 2002, e o segmento de turismo foi responsável pela arrecadação de R\$ 129 milhões de impostos, e pela criação de 160.582 empregos diretos e indiretos. 
A pesquisa revelou também que o turista gasta diariamente, por dia, em torno de $\mathrm{R} \$ 320,00$ e que a cidade possui 39 (trinta e nove) espaços para eventos.

Os espaços com maior destaque são:

- Centro de Convenções Ulysses Guimarães, com $49.849 \mathrm{~m}^{2}$, dotado de 4

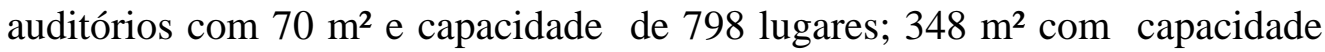
de 424 lugares; 252m² com capacidade de 248 lugares; 181m² com capacidade de 240 lugares, e uma área de exposições com $2.100 \mathrm{~m}^{2}$, que se encontra ultrapassado e sem capacidade para acomodar grande e médios eventos. Há, todavia, previsão de realização de reformas e construções, para a criação de uma área de exposição com 6.000 m², com um auditório com capacidade para 5.000 pessoas. Quando as obras estiverem todas concluídas, a sua capacidade total vai ser de 7.000 lugares. Haverá também uma praça de alimentação, teatros e galerias de lojas e cinemas. Sua reforma e ampliação está prevista para ficar pronta no final de 2004, e o custo previsto é de 40 milhões de reais.

- Centro de Convenções Blue Tree Park: 01 auditório com capacidade de 427 lugares, 14 salas de reuniões com divisórias removíveis.

- Centro de Convenções da Academia de Tênis.

- EXPOBRASÍLIA: com 53.000m² de área coberta, é o segundo maior da América Latina. Possui 38 boxes permanentes, posto telefônico, posto de correios, serviços de informações, entre outros. Tem também um anfiteatro com capacidade para 1.200 pessoas.

- Parque de Exposições da Granja do Torto: Eventos de grande porte, com 1.470.000 $\mathrm{m}^{2}$ de área, estacionamento para 40.000 carros, espaço para shows e praça de alimentação com $17.000 \mathrm{~m}^{2}$ de área, e outros.

- Centro de Convenções Israel Pinheiro: situado às margens do Lago Paranoá, numa área de 300 mil m².Com auditórios, salas de reunião, área de lazer, etc. 
O parque hoteleiro de Brasília teve seu inicio juntamente com a construção da capital Federal, o projeto da cidade já determinava as áreas destinadas para construção dos hotéis, cujo ficou definido em Setor Hoteleiro Norte e Setor Hoteleiro Sul onde concentra 91\% dos Hotéis do Plano Piloto, hoje apenas quatro hotéis faz uso e desfruto da opção do Lago Paranoá. Mas o primeiro hotel a inaugurar foi o Brasília Palace e 1958 localizado nas margens do Lago Paranoá, este hospedava o alto escalão do governo que vinha do Rio de Janeiro para planejar e administra a construção da capital e posteriormente hospedar o Presidente Juscelino Kubitschek e outras autoridades dos outros Países.

\section{FIGURA 1 - Setor Hoteleiro Sul}

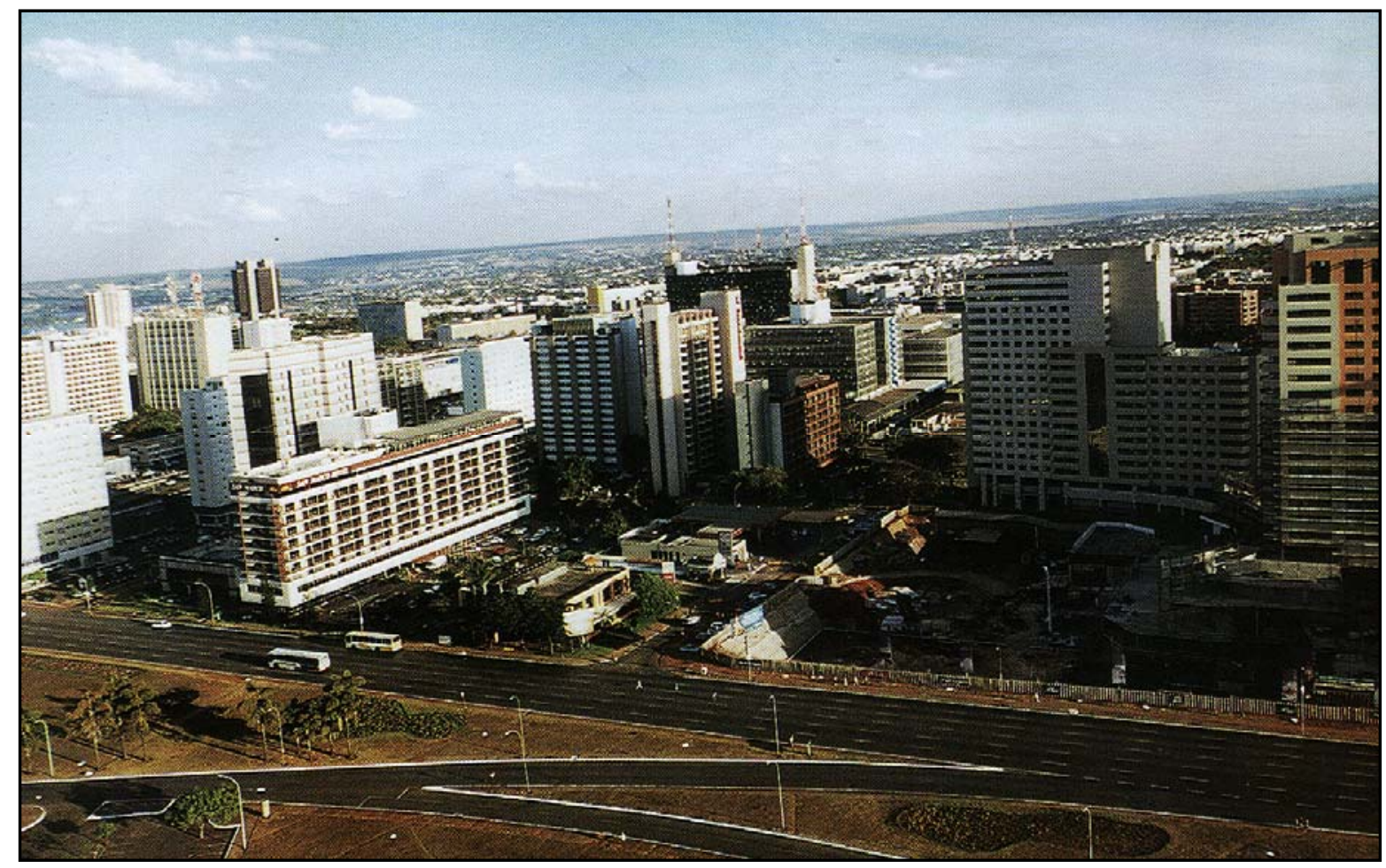




\section{FIGURA 2 - Setor Hoteleiro Norte}

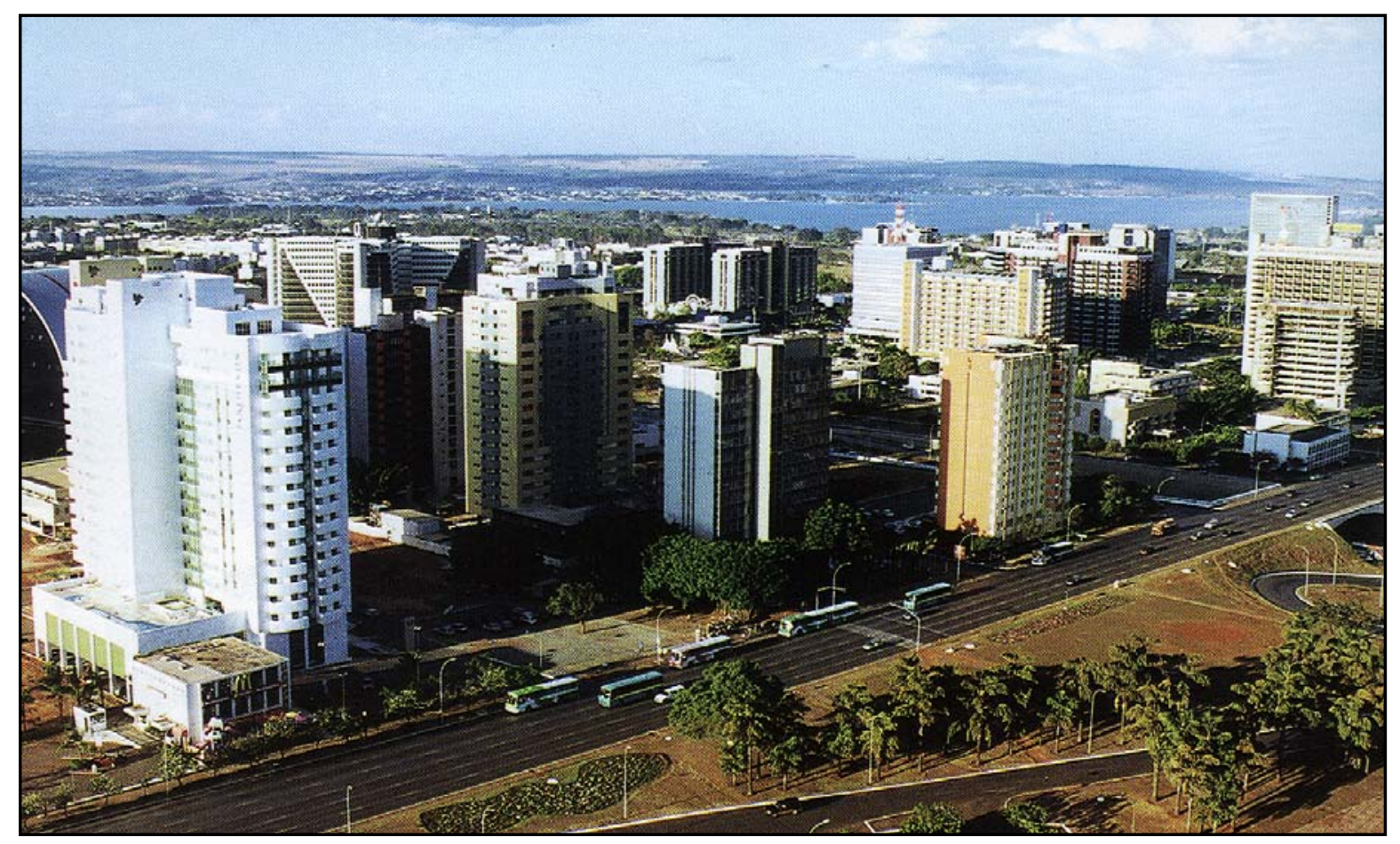

TABELA 12 - EVOLUÇÃO DO PARQUE HOTELEIRO DE BRASÍLIA

\begin{tabular}{r|l|c|c|c|c|c|c|c}
\hline \multicolumn{1}{|c|}{ Hotel } & $\begin{array}{c}\text { Inaugu- } \\
\text { ração }\end{array}$ & $\begin{array}{c}\text { Adminis- } \\
\text { tração }\end{array}$ & Categoria & Localização & UH's & ACUM. & VAR \% \\
\hline 1 & Brasília Palace & 1958 & Particular & $* * * * *$ & Lago Norte & 135 & 135 & 100,0 \\
2 & Brasília Imperial I & 1960 & Particular & s/class. & SHS & 34 & 169 & 20,1 \\
3 & Brasília Imperial II & 1960 & Particular & s/ class. & SHS & 34 & 203 & 16,7 \\
4 & Brasília Imperial & 1960 & Particular & s/ class. & SHS & 34 & 237 & 14,3
\end{tabular}




\begin{tabular}{|c|c|c|c|c|c|c|c|}
\hline Nacional & 1961 & Particular & $* * * * *$ & SHS & 360 & 597 & 60,3 \\
\hline Brasília Imperial IV & 1964 & Particular & s/ class. & SHS & 33 & 630 & 5,2 \\
\hline Brasíia Imperial V & 1964 & Particular & s/ class. & SHS & 42 & 672 & 6,3 \\
\hline Nações & 1965 & Particular & $* * *$ & SHS & 130 & 802 & 16,2 \\
\hline Itamaraty/ Econotel & 1968 & Particular & s/ class. & SHS & 50 & 852 & 5,9 \\
\hline Alvorada & 1970 & Particular & $* *$ * & SHS & 130 & 982 & 13,2 \\
\hline Diplomata & 1971 & Particular & $* * *$ & SHN & 44 & 1026 & 4,3 \\
\hline Byblos & 1972 & Particular & $* * *$ & SHN & 45 & 1071 & 4,2 \\
\hline Torre & 1973 & Particular & $* * * *$ & SHS & 165 & 1236 & 13,3 \\
\hline Eron & 1973 & Particular & $* * * *$ & SHN & 181 & 1417 & 12,8 \\
\hline Mirage & 1974 & Particular & ** & SHN & 196 & 1613 & 12,2 \\
\hline Aristus & 1974 & Particular & $* * *$ & SHN & 50 & 1663 & 3,0 \\
\hline Bristol & 1974 & Particular & $* * *$ & SHS & 145 & 1808 & 8,0 \\
\hline Américas & 1975 & Particular & $* * *$ & SHS & 149 & 1957 & 7,6 \\
\hline El Pilar & 1976 & Rede Bittar & ** & SHN & 64 & 2021 & 3,2 \\
\hline Casablanca & 1977 & Particular & $* * *$ & SHN & 58 & 2079 & 2,8 \\
\hline Academia Tênis $1^{a}$ Fase & 1977 & Particular & $* * * * *$ & Lago Norte & 68 & 2147 & 3,2 \\
\hline Saia Brasília Palace & 1978 & Particular & & Lago Norte & -135 & 2012 & $-6,7$ \\
\hline Carlton & 1979 & Particular & $* * * * *$ & SHS & 195 & 2207 & 8,8 \\
\hline Phenícia & 1980 & Rede Bittar & $* * * *$ & SHS & 130 & 2337 & 5,6 \\
\hline Saia Brasília Imperial V & 1981 & Particular & & SHS & -42 & 2295 & $-1,8$ \\
\hline Riviera & 1981 & Particular & $* * *$ & SHS & 42 & 2337 & 1,8 \\
\hline Academia Tênis $2^{\mathrm{a}}$ Fase & 1982 & Particular & $* * * * *$ & Lago Norte & 21 & 2358 & 0,9 \\
\hline Planalto & 1982 & Rede Bittar & $* * * *$ & SHS & 69 & 2427 & 2,8 \\
\hline St. Paul & 1983 & Particular & $* * * *$ & SHS & 271 & 2698 & 10,0 \\
\hline San Marco & 1983 & Particular & $* * * *$ & SHS & 204 & 2902 & 7,0 \\
\hline Saia Brasília Imperial III & 1984 & Particular & & SHS & -42 & 2860 & $-1,5$ \\
\hline Continental & 1985 & Particular & *** & SHN & 34 & 2894 & 1,2 \\
\hline Academia Tênis $3^{a}$ Fase & 1988 & Particular & $* * * * *$ & Lago Norte & 30 & 2924 & 1,0 \\
\hline Bittar Plaza & 1988 & Rede Bittar & *** & SHN & 97 & 3021 & 3,2 \\
\hline Brasília Park & 1989 & Particular & *** & SHS & 65 & 3086 & 2,1 \\
\hline Naoum & 1989 & Particular & $* * * * *$ & SHS & 187 & 3273 & 5,7 \\
\hline Kubitschek & 1990 & $\begin{array}{l}\text { Gr. P. } \\
\text { Octavio }\end{array}$ & $* * * * *$ & SHN & 245 & 3518 & 7,0 \\
\hline Manhattan & 1992 & $\begin{array}{l}\text { Gr. P. } \\
\text { Octavio }\end{array}$ & $* * * *$ & SHN & 315 & 3833 & 8,2 \\
\hline Monumental Bittar & 1992 & Rede Bittar & $* * * *$ & SHN & 111 & 3944 & 2,8 \\
\hline Academia Tênis $4^{a}$ Fase & 1992 & Particular & $\star * * * *$ & Lago Norte & 30 & 3974 & 0,8 \\
\hline 9 Bonaparte & 1994 & $\begin{array}{l}\text { Bluepoint } \\
\text { Ad. } \\
\text { Hoteleira }\end{array}$ & $* * * * *$ & SHS & 117 & 4091 & 2,9 \\
\hline Metropolitan Flat & 1996 & Atlantica $\mathrm{Ht}$ & $* * * * *$ & $\mathrm{SHN}$ & 240 & 4331 & 5,5 \\
\hline Academia Tênis $5^{a}$ Fase & 1996 & Particular & $* * * * *$ & Lago Norte & 70 & 4401 & 1,6 \\
\hline Saia Planalto & 1998 & Particular & & SHS & -48 & 4353 & $-1,1$ \\
\hline Blue Tree Towers & 2000 & Blue Tree & $* * * *$ & Lago Norte & 300 & 4653 & 6,4 \\
\hline Grand Bittar & 2000 & Rede Bittar & $* * * * *$ & SHS & 147 & 4800 & 3,1 \\
\hline Academia Tênis $6^{a}$ Fase & 2001 & Particular & $* * * * *$ & Lago Norte & 59 & 4859 & 1,2 \\
\hline Blue Tree Park & 2001 & Blue Tree & $* * * * *$ & Lago Norte & 394 & 5253 & 7,5 \\
\hline Quality Lake Side & 2001 & Atlantica $\mathrm{Ht}$ & $* * * * *$ & Lago Norte & 430 & 5683 & 7,6 \\
\hline
\end{tabular}




\begin{tabular}{|c|c|c|c|c|c|c|c|c|}
\hline 47 & Meliá Confort Park & 2001 & Sol Meliá & $* * * *$ & SHS & 260 & 5943 & 4,4 \\
\hline 48 & Parthenon & 2001 & $\begin{array}{l}\text { Accor } \\
\text { Hotéis }\end{array}$ & $* * * *$ & SHN & 274 & 6217 & 4,4 \\
\hline 45 & St. Peter & 2001 & Particular & $* * * *$ & SHS & 382 & 6599 & 5,8 \\
\hline 50 & Planalto Bittar & 2002 & Rede Bittar & $* * *$ & SHS & 103 & 6702 & 1,5 \\
\hline $51 \mid$ & Mercure & 2002 & $\begin{array}{l}\text { Accor } \\
\text { Hotéis }\end{array}$ & $* * * *$ & SHN & 358 & 7860 & 5,1 \\
\hline & Saia Continental & 2002 & Particular & & SHN & -34 & 8026 & $-0,5$ \\
\hline 52 & Meliá Brasília & 2003 & Sol Meliá & $* * * * *$ & SHS & 338 & 8364 & 4,6 \\
\hline 53 & Confort Suites Brasília & 2003 & Atlantica $\mathrm{Ht}$ & $* * * * *$ & SHS & 183 & 8907 & 2,4 \\
\hline
\end{tabular}

Fonte: Pesquisa de campo - questionários Hotéis de Brasília I e II , Brasília 2003

\section{GRÁFICO 2 - EVOLUÇÃO DO PARQUE HOTELEIRO DE BRASÍLIA}

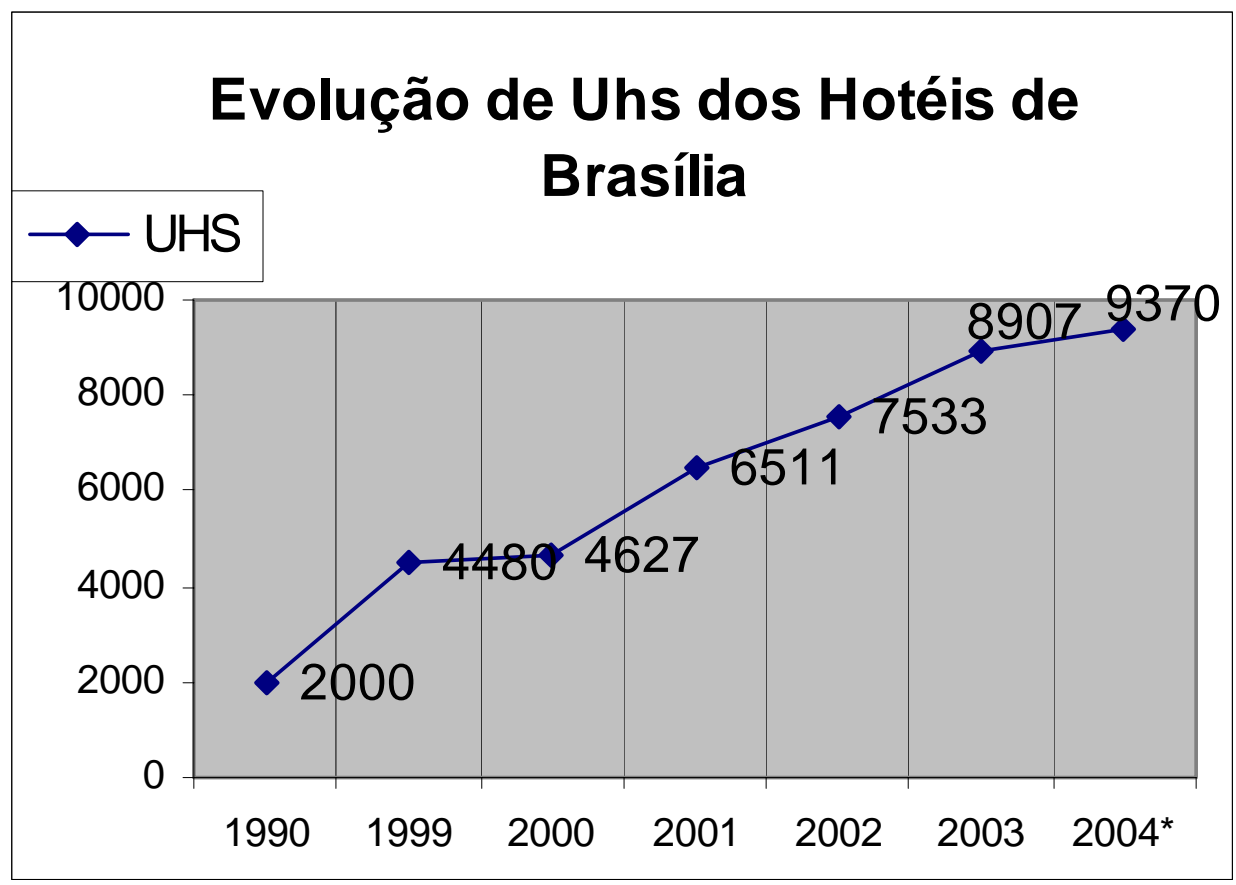

Fonte: Pesquisa de campo - questionários Hotéis de Brasília I e II , Brasília 2003

A evolução do Parque Hoteleiro de Brasília nos últimos anos é incontestável, tendo em vista que de 2000 até final de 2003 houve um aumento de 50\% na oferta de UH's, com isso, conseqüentemente, ocorreu também uma grande queda na ocupação média dos hotéis. Mediante o aumento de hotéis e em contra partida a falta de um Centro de Convenções que comporte grandes eventos e inevitável essa redução na ocupação nos hotéis.

Outro fato que o quadro 11 mostra é que dos últimos 11 hotéis inaugurados 10 tem administração de bandeiras internacionais ou nacionais. 


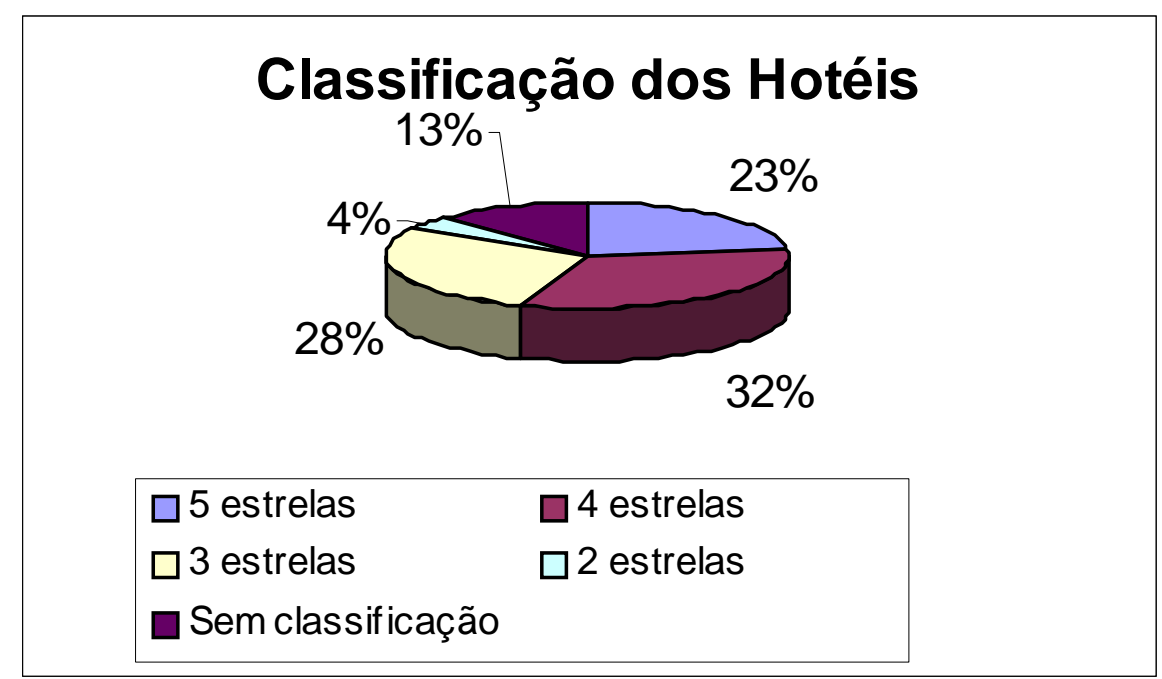

Fonte: Pesquisa de campo - questionários Hotéis de Brasília I e II , Brasília 2003

No tocante à classificação dos hotéis, foi observado que o que prevaleceu, em termos de maioria, foram os de 4 (quatro) estrelas, entretanto, é importante observar que o parque hoteleiro de Brasília é composto por 12 (doze) hotéis 5 (cinco) estrelas, o que corresponde a $\mathbf{2 3 \%}$. Os hotéis com 4 (quatro) estrelas, que correspondem a 15 (quinze), equivalem, em termos percentuais, a 32\%. Quanto aos 3 (três) estrelas, esses correspondem a 13 (treze), o que equivale a $\mathbf{2 8 \%}$., restando 2 os com 2 (duas) estrelas, que corresponde a 4\%. Finalmente, tem-se 6 (seis) hotéis sem classificação, o que dá 13\%. Dos últimos 17 (dezessete) inaugurados, apenas 1 (um) é de três estrelas; os demais, são 9 (nove) classificados com cinco estrelas e 7 (sete) com quatro estrelas. Isso também mostra que a tendência do mercado é de que cada vez mais a administração dos hotéis sejam geridas por grupos com bandeiras nacionais e internacionais. 


\section{GRÁFICO 4 - HOTÉIS DE BRASÍLIA - TIPO DE ADMINISTRAÇÃO}

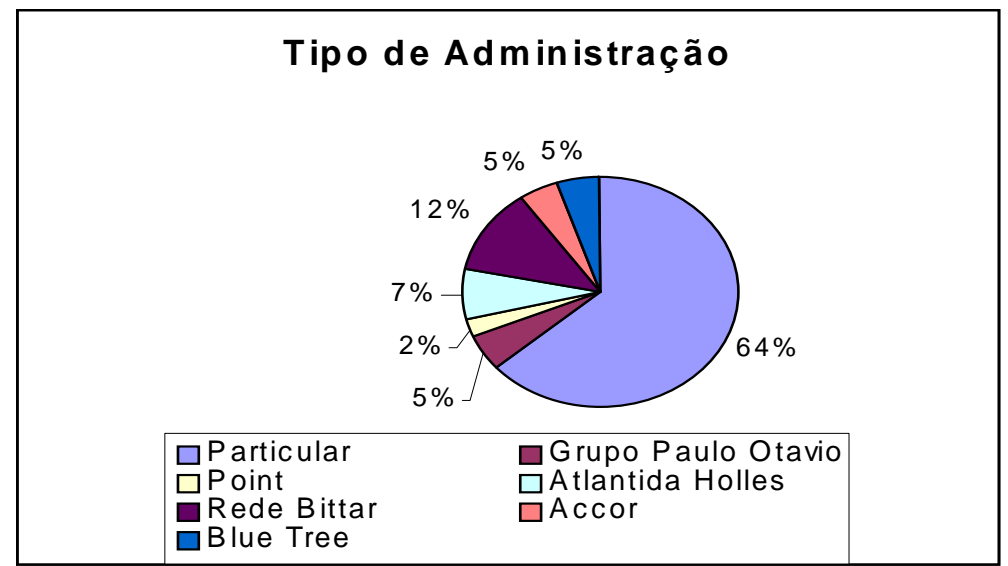

Fonte: Pesquisa de campo - Questionários Hotéis de Brasília I e II, Brasília 2003

Apesar de 64\% dos hotéis terem administração própria, entre os últimos 11 (onze) hotéis inaugurados, apenas 1 (um) tem administração própria. Os demais são com bandeiras internacionais ou nacionais. Com isso é possível perceber que as redes com

bandeiras internacionais e nacionais estão ganhando cada vez mais mercado, conforme a HIA - Hotel Investment Advisors apresenta em seu estudo de mercado "Hotelaria em Números - 2003”, destacando que nos últimos 5 (cinco) anos a construção de hotéis de três, quatro e cinco estrelas (que equivalem a 80\%) são administrados por bandeiras nacionais e internacionais.

\subsubsection{Ocupação Média dos Hotéis}

A ocupação média semanal da hotelaria quatro estrelas de Brasília consiste em : Nos meses de março a junho e agosto a novembro, totalizando uma média de 57\%. 


\begin{tabular}{c|c|c|c|c|c|c}
\hline SEGUNDA & TERÇA & QUARTA & QUINTA & SEXTA & SÁBADO & DOMINGO \\
$55 \%$ & $92 \%$ & $100 \%$ & $90 \%$ & $50 \%$ & $15 \%$ & $13 \%$ \\
\hline
\end{tabular}


Fonte: Pesquisa de campo - questionário Hotéis de Brasília II , Brasília

Nos meses de janeiro, fevereiro, julho e dezembro, totalizando uma média de $45 \%$.

TABELA 14 - HOTÉIS DE BRASÍLIA- OCUPAÇÃO NA BAIXA TEMPORADA

\begin{tabular}{c|c|c|c|c|c|c}
\hline SEGUNDA & TERÇA & QUARTA & QUINTA & SEXTA & SÁBADO & DOMINGO \\
$38 \%$ & $70 \%$ & $90 \%$ & $80 \%$ & $35 \%$ & $13 \%$ & $9 \%$ \\
\hline
\end{tabular}

Fonte: Pesquisa de campo - questionário Hotéis de Brasília II , Brasília 2003

GRÁFICO 5 - OCUPAÇÃO MÉDIA SEMANAL NA ALTA E BAIXA TEMPORADA

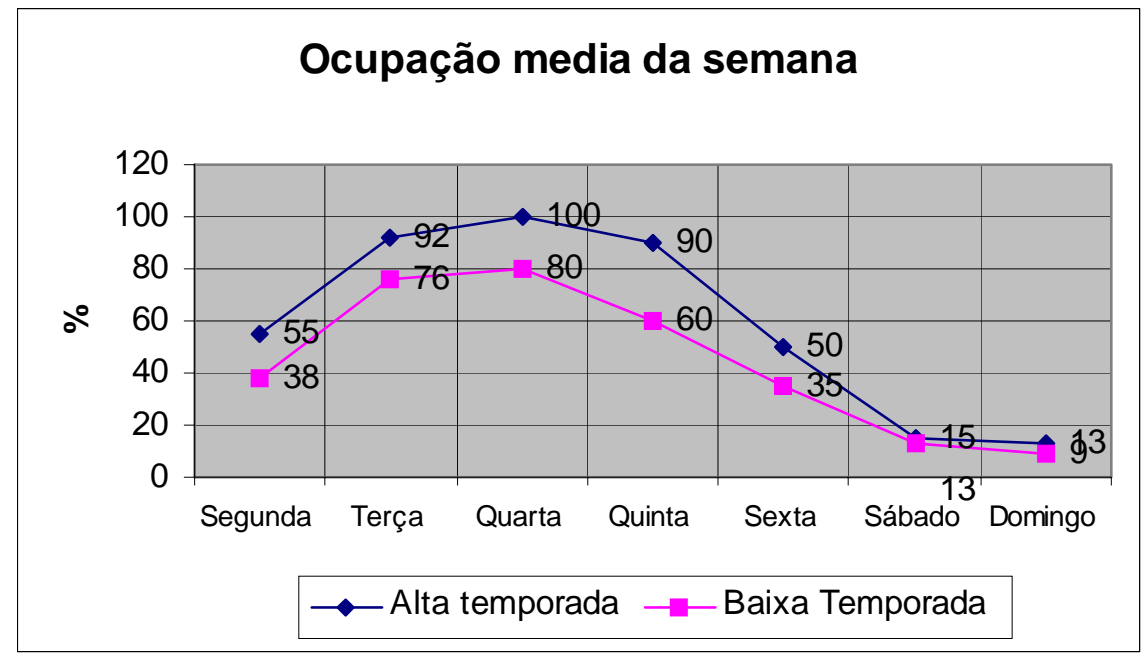

Fonte: Pesquisa de campo - questionário Hotéis de Brasília II , Brasília 2003

A ocupação média nos meses, totalizando em 52,25\%.

TABELA 15 - OCUPAÇÃO MÉDIA MENSAL DOS HOTÉIS

\begin{tabular}{c|c|c|c|c|c|c|c|c|c|c|c}
\hline JAN & FEV & MAR & ABR & MAI & JUN & JUL & AGO & SET & OUT & NOV & DEZ \\
\hline $35 \%$ & $41 \%$ & $51 \%$ & $59 \%$ & $56 \%$ & $59 \%$ & $53 \%$ & $55 \%$ & $56 \%$ & $59 \%$ & $62 \%$ & $41 \%$ \\
\hline
\end{tabular}

Fonte: Pesquisa de campo - Questionário Hotéis de Brasília II, Brasília 2003 


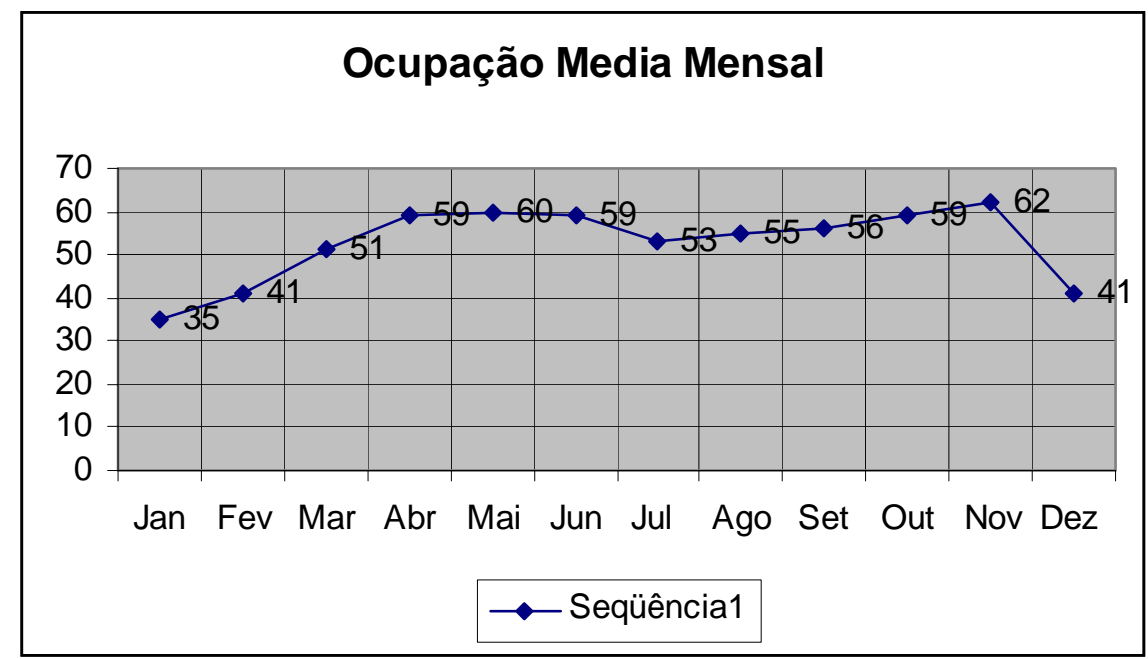

Fonte: Pesquisa de campo - Questionário Hotéis de Brasília II, Brasília 2003

A hotelaria de Brasília é considerada bem diferente das demais regiões do país. Como exemplo tem o do litoral, cujo período de alta temporada, que vai de dezembro a março e julho, é como o sul, que tem sua alta coincidindo com o inverno. Brasília também tem sua alta, que é no período que o Congresso Nacional está em funcionamento normal. Em função desse quadro é possível analisar que os hotéis locais têm um grande mercado a ganhar.

GRÁFICO 7 - HOTÉIS DE BRASÍLIA - DESCONTOS NOS FINAIS DE SEMANA

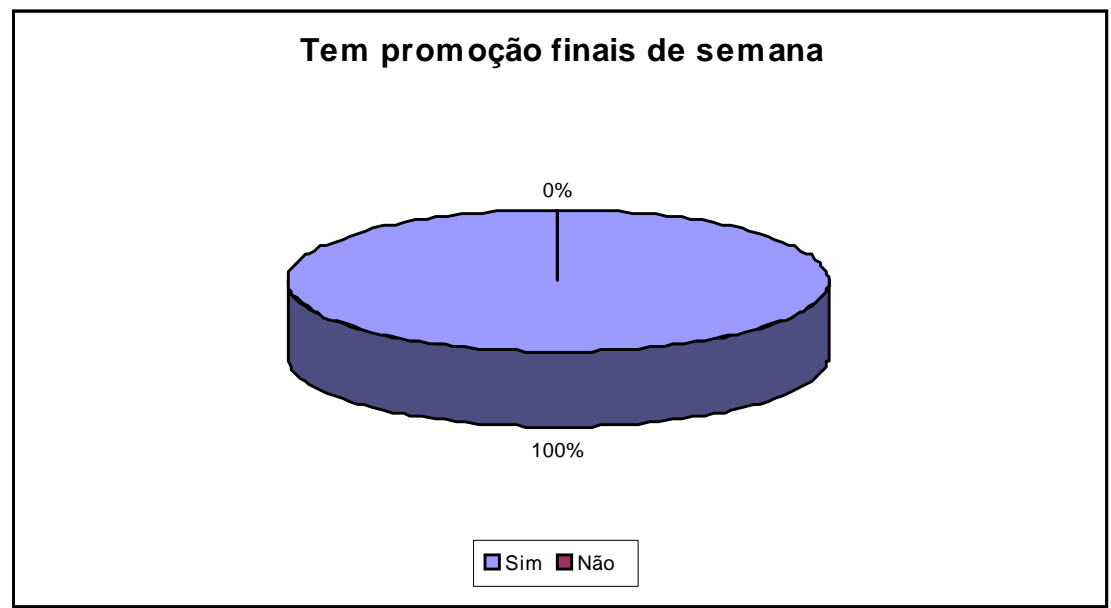

Fonte: Pesquisa de campo - Questionário Hotéis de Brasília II, Brasília 2003 
Foi detectado através da pesquisa que 100\% dos hotéis 4 (quatro) estrelas possuem descontos para os finais de semana, o desconto oferecido varia de $30 \%$ a $60 \%$ dependendo da quantidade de dias que o hóspede vai ficar hospedado, da época do ano e se a cidade está ou não sediando algum evento de grande porte .

Além dos descontos promocionais, outras promoções são oferecidos como:

- Na apresentação de dois ingressos de qualquer cinema os clientes terão de $50 \%$ a $60 \%$ na tarifa balcão, isto é, os preços podem variar de $\mathrm{R}$ 59,90 a R \$ 79,90 (quartos standard Duplo) com direito de usufruir toda instalação do hotel (piscina, sauna e academia, etc.).

- A título de incentivo, também, no final de semana, outros oferecem uma diária mais um jantar para duas pessoas inclusos na tarifa, a qual pode variar de R\$ 135,00 a R\$ 155,00, também com direito às instalações de hotel.

- Há outras promoções: se o pagamento for efetuado com cartão de crédito, essas diárias passam a um preço mais suave, entre R\$ 65,00 e R \$ 120,00.

A vantagem dessas promoções (infelizmente pouco divulgadas), é que se comparar esses preços com uma diária de motel, os valores poderão ser considerados até 4 (quatro) vezes maior, isto é, $\mathrm{R} \$ 215,00$ pela suíte mais simples. Lógico que este estudo não tem a intenção ou pretensão de transformar os hotéis em motéis, e sim, modestamente, constatar as possíveis falhas e tentar sugerir às suas administrações o diagnóstico para que possam alavancar suas ocupações nos finais de semana, o que seria mais uma alternativa para população local. 


\section{GRÁFICO 7 - HOTÉIS DE BRASÍLIA - DIVULGAÇÃO DE PROMOÇÕES}

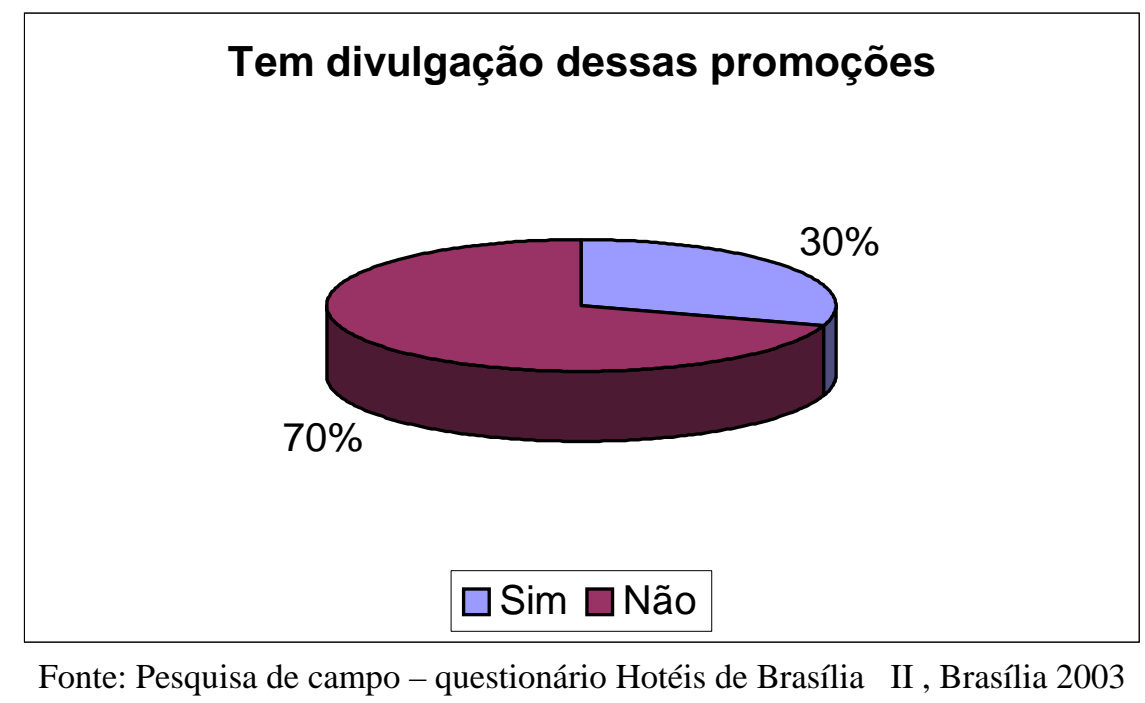

Poucos são os hotéis que trabalham a divulgação das promoções; que oferecem apenas 30\%, é fazem uso de meios de divulgação (com site, jornais, revista, e rádios), 70\% ficam na expectativa de que o cliente pergunte.

De posse dessa informação já podemos verificar uma falha no marketing dos hotéis, pois é mais que comprovado que uma divulgação é imprescindível para oferta de qualquer serviço ou produto.

Esta pesquisa constitui uma etapa fundamental para futura abordagem mais adensada ainda ao abrigo do Turismo Urbano e possibilidades do setor hoteleiro em Brasília. 


\section{CONCLUSÃO}

A pesquisa realizada, não obstante o seu cunho preliminar e exploratório, apontou aspectos curiosos e ao mesmo tempo preocupantes sobre a ocupação da rede hoteleira brasiliense nos finais de semanas, que incontestavelmente é uma das mais baixas do Brasil.

Nesse sentido, o relato dos gerentes entrevistados pelo autor é de que a ocupação dos hotéis de Brasília nos finais de semanas estão diretamente ligados aos eventos médios e de grandes portes que são realizados na cidade. Tirando essa demanda que ocorre com eventual freqüência, a ocupação fica muito a desejar, pois a falta de atrativos de lazer e os altos preços praticados na capital são os fatores mais relevantes na insatisfação dos turistas.

Além desses fatores negativos (divulgação e baixa ocupação), contribui negativamente a pouca ou quase total ausência de programação de lazer que os hotéis propiciam para atrair potenciais clientes da cidade e mesmo dos outros estados. Conseqüentemente, entende o autor que esses fatores são de grande relevância para dar alento ao Turismo em Brasília nos finais de semana.

Outro aspecto que o autor diagnosticou através da pesquisa realizada foi o fator negativo envolvendo a falta de parcerias dos hotéis com empresas de serviços de lazer e cultura que poderiam ser oferecidos aos seus hóspedes, proporcionando-lhes ter opções e acesso livre com essas empresas associadas. Na mesma linha de pensamento, foi percebido que as estruturas físicas dos 47 (quarenta e sete) hotéis pesquisados, apenas 4 (quatro) possuem espaços físicos para propiciar um melhor lazer aos seus hospede, no qual em função do plano urbanístico da cidade, impossibilitou os hotéis a terem espaços mais amplos horizontalmente, restringindo e muito a construção dessas áreas.

Outro fator observado foi a questão do marketing, pois a maioria dos hotéis não trabalham a divulgação de suas promoções e serviços prestados nos finais de semana, e mesmo dos folders dos 47 (quarenta e sete) hotéis estudados, apenas 4 (quatro) o fazem. Os folders, por sua vez, concentram apenas seu enfoque no trivial que têm para oferecer aos clientes, deixando de lado a possibilidade de se mencionar as tão importantes promoções. 
No conjunto a pesquisa aponta para algumas iniciativas que viabilizaria a alavancar a ocupação dos hotéis nos finais de semana. É o caso por exemplo de trabalhar a infra-estrutura da cidade, com a atenção voltada para a reforma e a construção de um auditório (com acústica adequada) no EXPOBRASÍLIA.

Estudou, constatou e por fim concluiu o autor que elaborar e implementar um plano de desenvolvimento da indústria do Turismo, para formular alternativas de crescimento do setor e estabelecer objetivos, metas e estratégias de curto, médio e longo prazo, com parcerias dos empresários na área e serviços com o Governo do Distrito Federal. Dentro dessa ótica, constatou o autor as seguintes necessidades imediatas: complementar a infraestrutura dos setores Hoteleiros Norte e Sul, com atenção especial para iluminação pública, urbanização, segurança e sinalização.

Estruturar e implementar os projetos para o Lago Paranoá, com infra-estrutura adequada e cuidados quanto à segurança dos freqüentadores e à preservação ambiental, tal como Projeto Orla, com atração de lazer e eventos (Projeto do Governo do Distrito Federal).

Desviando o enfoque específico dos hotéis do Plano Piloto, sugeriria o autor a criação de roteiros turísticos que explorassem as oportunidades oferecidas por Brasília e regiões do entorno.

Percebeu o autor que ideal seria a adoção de políticas de incentivos fiscais e de crédito para a ampliação de programas de capacitação profissional, tecnológica e gerencial, voltadas especialmente para os micro, pequenos e médios empreendedores do turismo.

A indústria de eventos é um grande aliado para alavancar também a ocupação da rede hoteleira de Brasília, tem sua importância ainda ampliada se for considerado que, por meio deles, os negócios que envolve os eventos gera muitos emprego e renda. Outras estratégias envolvendo o assunto, de modo a serem consideradas, segundo o autor, seriam: a) que trabalhem a divulgação dos serviços oferecidos nos finais de semana como também elaborarem promoções para datas comemorativas como aniversários de casamentos e namoros para casais da cidade, promovendo todo um ambiente e atrações com jantares a luz 
de velas, bailes românticos e atrações que o hotel tem para oferecer; b) Aproveitar as áreas de eventos para casamentos, utiliza salões do hotel para cerimônia e festa juntamente com serviços de A\&B - Alimentos e Bebidas. É aproveitar a situação disponibilizando suítes e salões de beleza para os noivos e convidados; c) Fecha pacotes com escolas de outras cidades, para alunos passarem um final de semana na Capital do País, com o dia cidadão. Mostrando a eles como funciona os poderes Legislativo, Executivo e Judiciário, tendo também no roteiro atividades de lazer.

Preocupou-nos, sobremaneira, sobretudo porque nos consideramos apaixonados pelo tema em apreço, a questão da enorme redução do percentual de turistas que visitam Brasília com intuito específico de fazer turismo. Essa queda é um dos pontos que mostra a falta de entrosamento dos empresários do setor, inclusive, provavelmente, um interesse não menor por parte das autoridades governamentais que cuidam do assunto. 


\section{CORPUS DA PESQUISA}

O corpus da pesquisa foi construído com as seguintes fontes.

\section{1- Fontes Escritas.}

1.1 Material disponibilizado pela ABIH Associação Brasileira da Indústria de Hotéis e do C\&B Convention \& Visitors Bureau.

1.2 Questionários (vide modelos em anexo).

1.2.1 Questionário (Hotéis de Brasília I) com questões fechadas aplicado em 47 hotéis da rede hoteleira de Brasília.

1.2.2 Questionário (Hotéis de Brasília II) aplicado com 5 hotéis do Plano Piloto categoria 4 estrelas.

2- Fontes Iconográficas.

2.1 fotos

2.2 Folders (vide anexo) 


\section{REFERÊNCIAS BIBLIOGRÁFICAS}

BENI, Mário Carlos. 1998. Análise Estrutural do Turismo. 2. ed. São Paulo: Ed.do SENAC.

CASTELLI, Geraldo. 2001. Administração Hoteleira. 9.ed. Caxias do Sul: EDUCS.

EMBRATUR. Estudo da Demanda Turística Internacional - 2001. Brasília, 2001.

. Evolução do Turismo no Brasil - 1992/2001 - Brasília 2000.

. Anuário Estatístico. Brasília: 2002.

. Estudo do Turismo Brasileiro - 1999.

FAHEY,Lima. MBA: Curso Prático: Estratégia. Rio de Janeiro : Campos, 1999.

KUAZAQUI, Edmir. Marketing Turístico e de Hospitalidade. São Paulo: Makron Books, 2000.

LARA, Simone B. Marketing \& Vendas na Hotelaria. São Paulo: Futura, 2001.

OLIVEIRA, Antonio Pereira. Turismo e Desenvolvimento - Planejamento e Organização. 2. ed. São Paulo: Atlas, 2002.

PETROCCHI, Mario. Hotelaria: Planejamento e Gestão. São Paulo: Futura, 2002.

TIBONI, Conceição Gentil Rebelo. 2002. Estatística Básica para o Curso de Turismo. São Paulo: Atlas, 2002.

SEBRAE. I Dimensionamento Econômico da Indústria de Eventos no Brasil - 2001/2002

- Principais Conclusões.

VAZ, Gil Numo. Marketing Turístico: Receptivo e Emissivo: Um Roteiro Estratégico Para Projetos Mercadológicos Públicos e Privados. São Paulo:Pioneira, 2001.

ZANELLA. Luiz Carlos. 2001. Administração de Custos em Hotelaria. 2 ed. Caxias do Sul: EDUCS. 
ANEXOS 


\section{ANEXO 01}

Questionário : Hotéis de Brasília I

Hotel :

Inaugurado:

UH:

Leitos:

Estrelas:

Administração : 


\section{ANEXO 02}

Questionário : Hotéis de Brasília II

Hotel :

Inaugurado:

$\mathrm{UH}:$

Leitos:

Estrelas: Administração :

Ocupação : semanal

\begin{tabular}{|l|l|l|l|l|l|l|}
\hline SEGUNDA & TERÇA & QUARTA & QUINTA & SEXTA & SABADO & DOMINGO \\
\hline & & & & & & \\
\hline & & & & & & \\
\hline & & & & & & \\
\hline
\end{tabular}

Ocupação : mensal

\begin{tabular}{|l|l|l|l|l|l|l|l|l|l|l|l|}
\hline JAN & FEV & MAR & ABRI & MAIO & JUN & JUL & AGO & SET & OUT & NOV & DEZ \\
\hline & & & & & & & & & & & \\
\hline & & & & & & & & & & & \\
\hline
\end{tabular}

O Hotel tem alguma promoção

nos finais de semana? Sim

Não . Se sim

Qual ?

O Hotel tem alguma divulgação dessas promoções dos finais de semana? Sim $\square$ Não $\square$ . Se sim Qual ? Se não qual o motivo de não ter divulgação.

O Hotel já teve alguma promoção nos finais de semana? Sim $\square$ Não $\square$. Se sim Qual ? Se não qual o motivo de não ter havido divulgação. 
O Hotel tem ou já fez alguma parceria com alguma atração de lazer ou cultura na cidade ou entorno? Qual ? Resultados?

Quais as razões que os hospede alega de não ficar nos finais de semana em Brasília?

Quais os tipos de entretenimento que os hospede cobram em relação a Brasília?

Quais as atrações de lazer que o Hotel tem para oferecer aos hóspedes?

Na sua opinião, o que falta para alavancar a ocupação dos Hotéis nos finais de semana em Brasília?

No Hotel

Em Brasília 
Qual o percentual dos hospede que ocupa o Hotel de segunda a sexta de sexta-feira a domingo?

\begin{tabular}{|l|l|l|l|}
\hline & Segunda a Quinta & Sexta a Domingo & \\
\hline Turista & & & \\
\hline Negócios & & & \\
\hline Mensalista & & & \\
\hline Outros & & & \\
\hline
\end{tabular}


ANEXO 03

Folders 


\begin{tabular}{|c|c|}
\hline 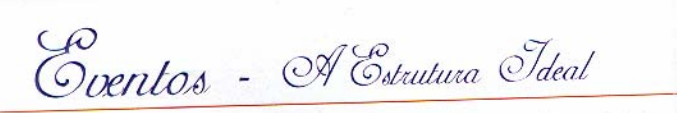 & $\begin{array}{l}\text { - } 3000 \text { metros quadrados de salões e salas } \\
\text { - Várias modalidades de montagem } \\
\text { - Sistema de som e tradução simultânea }\end{array}$ \\
\hline Completa infra-estrutura para convenções, simpósios, & $\begin{array}{l}\text { - Serviço completo de coordenaçao e apoio } \\
\text { - Estacionamento privativo }\end{array}$ \\
\hline
\end{tabular}

coquetéis e banquetes.

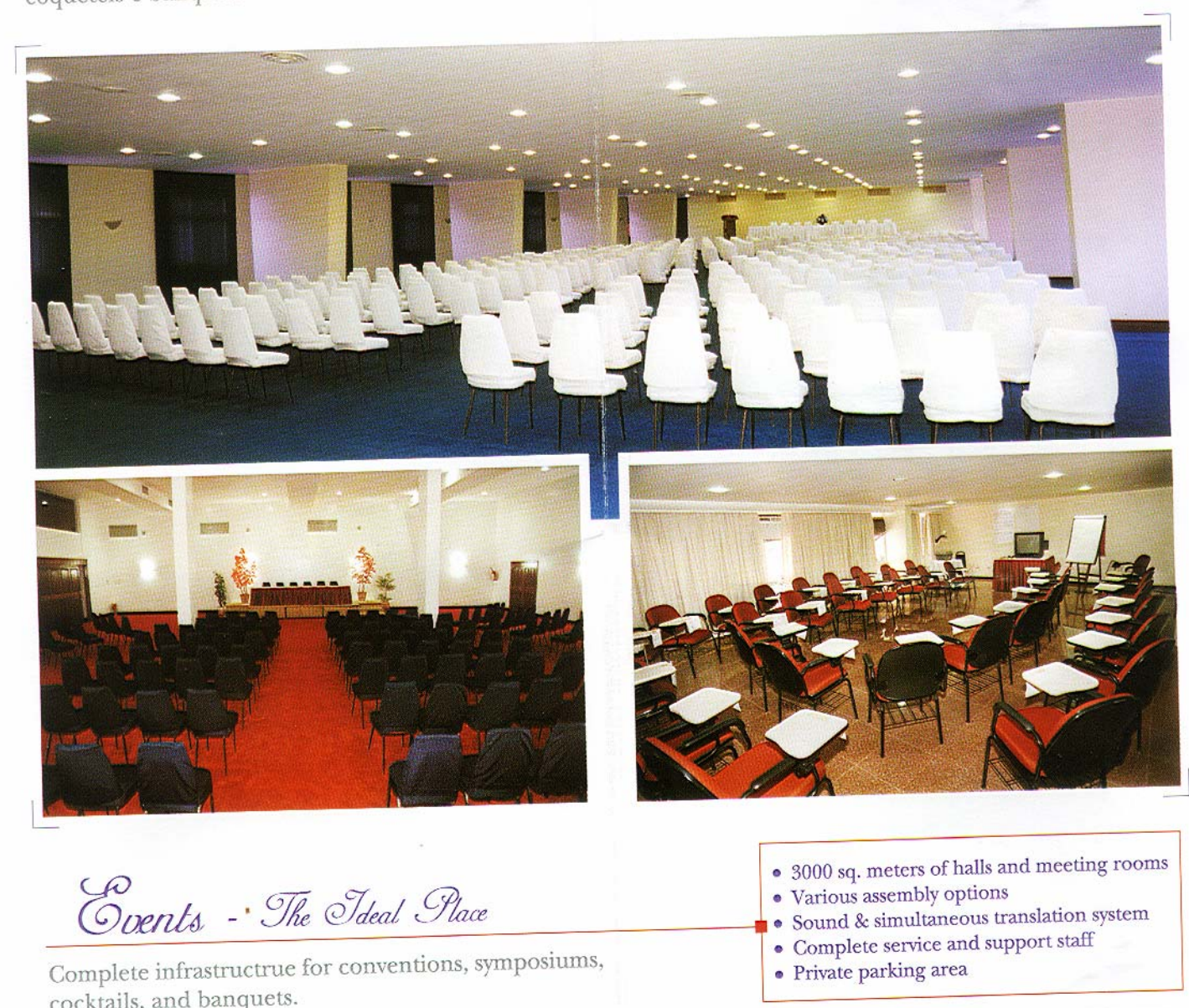

